\title{
EVALUACIÓN CIUDADANA DE LA PUBLICIDAD ENGAÑOSA: CONDICIÓN PARA LA GOBERNANZA DE LA CIENCIA Y LA TECNOLOGÍA
}

Raúl Alberto Domínguez Rendón ${ }^{1}$

Director de Cultura del Instituto Tecnológico Metropolitano -ITM-. Institución Universitaria

Correo Electrónico: rauldominguez@itm.edu.co

Resumen: En este artículo se despliegan algunos criterios claves presentes en la conceptualización sobre el carácter público de las discusiones en torno a la ciencia y la tecnología, como condición para una práctica democrática y participativa de la ciudadanía en el mundo actual. Igualmente, se abordan algunas normas que procuran regular la publicidad de productos de consumo donde la innovación tecnocientífica es el argumento central y se ejemplifican algunos anuncios donde se vulneran algunas de esas prescripciones orientadas a mejorar la gobernanza del proceso comunicativo.

Historiador, Especialista en Semiótica y Hermenéutica del Arte, Magister en Estética de la Universidad Nacional de Colombia, candidato al Doctorado en Estudios de Ciencia y Tecnología de la Universidad del País Vasco (España).

Fecha de recepción: 30 de junio de 2009

Fecha de aceptación: 29 de agosto de 2009
Palabras clave: publicidad engañosa, cultura científica, cultura tecnológica, gobernanza, alfabetización ciudadana.

Abstract: This article display some key criteria present in the conceptualization about the public nature of the discussions concerning science and technology, as a condition for democratic practice and participatory citizenship today. It also addresses some rules that seek to regulate the advertising of consumer products where the techno-scientific innovation is the central argument and exemplified some ads which violate some of these requirements aimed at improving the governance of the communicative process.

Key Words: deceptive advertising, scientific culture, technological culture, governance, civic literacy. 


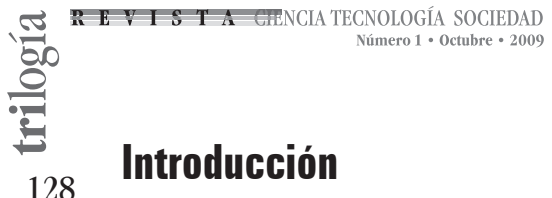

128

Una de las principales características que distinguen a la denominada sociedad del conocimiento es el nuevo repertorio de interrelaciones que se dan entre ciencia, tecnología, sociedad y política. Cada vez más el bienestar presente y la supervivencia futura de los humanos dependen de la generación y aplicación de conocimientos científicos y tecnológicos. Incluso, podríamos aventurarnos a decir que hoy es más abundante la producción científica y tecnológica, comparada con las producciones estéticas, literarias y artísticas de muchos siglos de historia humana. Eso lleva a que prácticas como la ciencia y la tecnología, su financiación, la explotación de sus resultados, su divulgación 0 institucionalización, en otras palabras, su impacto y responsabilidad sobre el futuro de nuestra sociedad, sean asuntos demasiado importantes para la mayoría de los ciudadanos que no se pueden dejar exclusivamente en manos de unos cuantos científicos, sabios o expertos.

Como trataremos de mostrar, un cierto nivel de comprensión de la ciencia y de la tecnología es necesario para poder vivir en sociedades avanzadas cientifica y tecnológicamente.

De ese modo, los ciudadanos estarían mejor preparados para tomar múltiples decisiones cotidianas sobre alimentación y salud, prevención y seguridad así como para poder evaluar de manera más informada los mensajes publicitarios que pueden llegar a ser engañosos y adoptar las mejores elecciones como consumidores (Blanco, 2004).

El trabajo presentado aquí no pretende mostrar resultados de una investigación de largo aliento sobre el tema sino reseñar las conclusiones de un primer acercamiento más bien general al problema que se realizó en el marco de la Cátedra Abierta CTS 2008 del ITM que en su primera versión se dedicó al tema de la Gobernanza de la Ciencia y la Tecnología. Como antecedentes, desde los años setenta del siglo XX, se publicaron algunos trabajos importantes acerca de la interpretación semiótica e iconográfica de la imagen publicitaria así como sobre su rol en la sociedad de masas (Marmori, 1977; Victoroff, 1980; Floch, 1993 y Qualter, 1994). Simultáneamente, otros estudios, algunos inspirados en los pioneros estudios críticos de Packard (1957 y 1960), tomaron un tono más de denuncia ideológica respecto a las estrategias de engaño y manipulación presumiblemente utilizadas por la publicidad y, particularmente, sobre el manejo de la imagen femenina (Durandin, 1982; Guinsberg, 1987; Perez Tornero, 1992; Pérez, 1997 y Martínez, 2003). Ahora bien, bajo el título específico de "publicidad engañosa" (deceptive advertising), vale la pena destacar el texto de Richards (1990), que presenta una completa investigación conceptual sobre aspectos legales y del comportamiento del problema, sobre todo en el contexto norteamericano; para el caso colombiano, está la tesis de grado de Castillo (1999), donde se compara la legislación local que trata de proteger al consumidor respecto a este tipo de prácticas con la de países europeos.

En lo que sigue, reseñaré algunos planteamientos centrales respecto a las relaciones entre cultura científicatecnológica y participación ciudadana, luego presentaré algunas regulaciones colombianas que buscan controlar prácticas publicitarias en el campo de los alimentos y los medicamentos y, finalmente, mostraré de manera sucinta algunos ejemplos de publicidad que, recurriendo a argumentos de innovación científica y tecnológica, tienden a violar las disposiciones contempladas en esas normas. Dado el alcance del estudio, para la selección de ejemplos publicitarios se optó por recoger una pequeña muestra de anuncios de prensa escrita (6 meses, entre enero y junio de 2008) donde se tuvieron en cuenta datos contenidos tanto en las imágenes y textos de los mensajes como en los empaques de los productos en ellos exhibidos. Como medio de comunicación se optó por la Revista Semana por 
tratarse de un medio escrito que, aunque dirigido a un público de clase media y alta, tiene un alcance nacional: más de un millón de lectores al mes según Estudios Generales de Medios citados por la misma publicación.

\section{Carácter público y no supersticioso de la ciencia y la tecnología en la sociedad del conocimiento.}

En el mundo actual el conocimiento es un recurso tan poderoso que no es posible la construcción de una sociedad democrática si el conocimiento se mantiene como una propiedad de elites cerradas: "Sólo en la medida en que el público tenga una participación real en los debates de ciencia y tecnología y las prácticas científicas se reconozcan como parte de la cultura, tendremos una sociedad con mejores capacidades para construir conocimientos adecuados a sus intereses" (Nieto, 2002, p. 82). Cada vez más las decisiones de ciencia y tecnología son objeto de debates políticos y de conflictos sociales en un contexto donde éstas, precisamente por su inusitado e increíble desarrollo, todavía generan muchas incertidumbres, riesgos ambientales y desafíos éticos. Las industrias del siglo XX eran auténticas "cajas negras" de las que brotaban productos pero nadie sabía cómo se producían.

En este contexto, los investigadores y científicos guardaban celosamente sus proyectos, amparados en el secreto industrial y bajo el temor de que sus colegas les robaran sus ideas y les ganaran la carrera por el premio Nobel.

De ese modo, la ciencia se encerró en una torre de marfil en la que sólo unos pocos privilegiados podían acceder a ella (Guzmán, 2007, p. 3). No obstante, este panorama tiende a cambiar y esas "cajas negras" (industrias, centros de investigación y desarrollo) han tenido que ir exponiéndose, por lo menos, a la vista de algunas comunidades ante las que tienen que rendir cuentas respecto a los impactos y riesgos que generan sus proyectos. En la medida que se va entendiendo que la investigación es pública por su misma naturaleza, un nuevo paradigma se impone y universidades prestigiosas y grandes empresas, incluso para lograr su competitividad en mercados abiertos, ya se organizan en redes colaborativas donde el conocimiento puede fluir con un poco más de libertad, tal como lo muestran Tapscott y Williams en su célebre trabajo Wikinomics: How mass collaboration changes everything (2006).

Umberto Eco en una conferencia sobre la recepción de la ciencia por parte de la opinión pública y los medios de comunicación publicada como El mago y el científico (2002), critica la visión de un mundo que, por encima de cualquier otro tipo de valores, se fundamenta en la confianza ciega en las verdades absolutas de la ciencia y en el poder incuestionable de la tecnología. Puso en evidencia una época embelesada por la velocidad y la instantaneidad de cada nueva innovación, donde se consiguen los efectos (artefactos y servicios novedosos) de manera mágica y sin tener que considerar 0 explicar las causas, procesos 0 pasos intermedios. Ese deseo de simultaneidad de causas y efectos, propia de los ritos mágicos y supersticiosos, se ha trasladado a la ciencia y a la tecnología, cuyos usuarios viven como por encanto sus interacciones con las omnipresentes "cajas negras". Y es el aspecto fantástico de esa visión de la ciencia y la tecnología el que tienden a transmitir los medios de comunicación: los resultados de investigación se comunican como "descubrimientos", "revoluciones" y "milagros" que lograrán, por fin, la anhelada felicidad de la humanidad. Se olvida que la investigación en una ciencia no acabada siempre está en construcción y que se hace con hipótesis, experimentos, pruebas y falsaciones que hacen tortuoso el camino y no tan idílico como parece.

\section{La educación y los medios de comunicación cumplen un rol en la formación cultural ciudadana en ciencia y tecnología}

¿Tendrá alguna utilidad pedir a los medios de comunicación que abandonen esa mentalidad mágica y sensacionalista que tantos réditos les reporta? Aquí, es donde la escuela, 
desde primaria hasta la universidad y todas sus alternativas "extracurriculares", juegan un rol trascendental en términos de la formación de niños y jóvenes en una concepción desmitificada de la ciencia y la tecnología, como lo propone Eco (2002): "La conclusión polémica de mi intervención es que el presunto prestigio de que goza hoy el científico se basa en razones falsas, y está en todo caso contaminado por la influencia conjunta de las dos formas de magia, la tradicional y la tecnológica, que aún fascina la mente de la mayoría. Si no salimos de esta espiral de falsas promesas y esperanzas defraudadas, la propia ciencia tendrá un camino más arduo que realizar".

En algunos estudios (Gutiérrez et al, 2002) se ha mostrado que existe una tendencia, entre estudiantes, intelectuales y comunicadores, a desconocer la ciencia como parte del acervo cultural de los ciudadanos y a considerar como "incultas" a las personas que carecen de conocimientos "humanísticos", pero, a la vez, a no otorgar el mismo calificativo a quienes tienen conocimientos deficientes sobre ciencia y tecnología. Sabemos que la ciencia y la tecnología juegan un papel determinante en los mundos natural y artificial, pero en su divulgación se asumen como una especie de "segunda cultura", diferente de la cultura cotidiana y de la que se podría incluso prescindir. Este enfoque deja abiertas preguntas como: ¿Pueden hoy participar democráticamente los ciudadanos en la sociedad sin una formación en cultura científica y tecnológica? ¿Qué ciencia se enseña en la escuela y cómo se enseña? Como muestran los autores, se comunica la imagen de una ciencia "altamente tecnificada, especializada y elitista, sólo apta para unos cuantos privilegiados portadores del saber. Una ciencia alejada de la sociedad y de los problemas sociales" (Gutiérrez et al, 2002, p. 26).

Para el caso de América Latina, Polino (2004) muestra como muchas frustraciones actuales se originan en el fracaso de los optimistas ideales que enarbolaron las revoluciones científicas y tecnológicas que vaticinaban el progreso social y la resolución final de los problemas de la humanidad: los sueños de la razón más bien engendraron monstruos. Con este fracaso del proyecto de la modernidad, se profundizó la brecha que trazaron los hombres de la Ilustración entre la sociedad o cultura comunes y la actividad científica como experiencia sagrada reservada sólo a espíritus encumbrados. Este hecho ha marcado un enfoque unidireccional y jerárquico de la divulgación científica: "La distancia entre los científicos y el resto de la sociedad se define como un problema de educación, de conocimiento, de déficit. Lógicamente, no existe ciencia por un lado y cultura por otro, hay ciencia en la cultura" (Polino, 2004). Así, entre el público predomina la idea de la ciencia como un santuario para elegidos que lleva a quien no lo respeta reverencial y solemnemente a la reputación de anticientífico e irracional. Según la hipótesis de Polino, esa separación entre "sabios" e "ignorantes" transformó la comunicación de la ciencia de una pedagogía (enseñaraprender) a una simple alfabetización 0 instrucción donde el hueco en la cabeza del público inepto es atiborrado de "conocimientos" de un nivel inferior. Una cultura científica coherente con las dinámicas sociales y los discursos cotidianos "debería entenderse entonces como la capacidad de la sociedad para incorporar la actividad científica en la agenda de los temas sociales, en la medida en que la misma sea funcional a los objetivos de la sociedad. Dicho de otro modo, en una correcta articulación que rescate los mejores valores intrínsecos del rumbo de la modernidad" (Ibid).

Al respecto, en sus reflexiones críticas sobre la "cultura científica", Lévy-Leblond (2003, p. 139) plantea que "debe abandonarse la concepción de que existen por un lado los legos y por el otro los poseedores del saber: los conocimientos de los científicos son limitados y su validez está estrechamente circunscripta. Esto da lugar a que no exista realmente una cultura científica". La única salida a esta encrucijada que ve este autor es "reinsertar la ciencia en la cultura a través de una modificación profunda de la actividad científica y de la formación de sus profesionales, que incluya para ambos casos los elementos para la comprensión de la historia de las ciencias y sus aspectos filosóficos, sociológicos y económicos" (Ibid). 
En medio de su vano triunfalismo, es innegable hoy cierta crisis de credibilidad ética de la ciencia que conlleva a la pérdida de apoyos políticos y económicos y a cierta reivindicación de discursos catastrofistas y apocalípticos.

Se ha pensado que esa falta de aprobación y de apoyo irrestricto a la ciencia se debe al desconocimiento e incomprensión de la ciencia por parte del público lego y que, en consecuencia, lo que está es juego es una simple cuestión de comunicación o difusión de la ciencia desde el modelo del déficit de saberes. Se pierde de vista que se trata de una cuestión de poder, de la posibilidad de lograr mucha más democracia respecto a las elecciones científicas y tecnológicas de los ciudadanos, de que éstos puedan también ejercer, de manera más ilustrada, el derecho de deliberar e incidir en las orientaciones de la investigación y el devenir de la tecnociencia.

\section{Cultura tecnocientífica, comunicación y participación de los ciudadanos en los destinos de la sociedad}

En una sociedad impregnada hasta el tuétano de una tecnociencia cuyo desarrollo no está predeterminado, es imprescindible que existan políticas para una adecuada divulgación de información sobre la ciencia y la tecnología como condición clave para el perfeccionamiento de la democracia y para la conquista de una praxis más racional y participativa de los ciudadanos. Como muestran Marcos y Calderón (2002, p. 26): "El sistema de divulgación de la ciencia se ha convertido en un nodo de interacción entre ciencia, tecnología, sistema político y público, entendido éste en sus diversas facetas de ciudadano, consumidor, votante, contribuyente, afectado". Y en dicho sistema se debe incluir entre sus contenidos información sobre los resultados y logros, los procesos y métodos científicos y tecnológicos, así como sobre sus incertidumbres y errores, sus aplicaciones y riesgos, su naturaleza y sus impactos de todo tipo en la sociedad, en los individuos y en el medio ambiente. Para estos autores, "la mejor forma de teorizar las funciones de la divulgación de la ciencia es pensándola como un sistema abierto, adaptativo y social. En efecto, el sistema de divulgación de la ciencia está en estrecha conexión con otros sistemas sociales, básicamente con el científico, tecnológico y político, pero también con el económico, jurídico, ético, militar o artístico entre otros" (Marcos y Calderón, 2002, p. 12).

La comunicación y la interacción social de múltiples actores son las principales condiciones para que exista conocimiento y éste adquiera sentido;

en ese contexto, la producción del conocimiento no se puede separar de los mecanismos para su divulgación y legitimación, por lo tanto "la apropiación pública de la ciencia no puede ser entendida como un suplemento 0 actividad posterior y diferenciable de la producción misma de conocimiento. Es necesario abandonar la idea de que el conocimiento existe de manera independiente de la sociedad en que circula y examinar con más cuidado los procesos de comunicación o de comprensión pública de la ciencia que asumen que el significado del conocimiento existe antes de su uso" (Nieto, 2002, p. 81).

La inadecuada separación entre los contextos de producción-descubrimiento y de divulgación-legitimación del conocimiento ha contribuido a mantener y extender la brecha entre lo tecnocientífico y otras formas de cultura, entre "expertos" y "legos". Desde esa perspectiva, los programas de apropiación pública de la ciencia y la tecnología por mucho tiempo tuvieron como único fin que el público no especializado estuviera familiarizado sólo con los conceptos básicos de ambas y con sus productos acabados pero sin conocer sus contextos y sin asumir un rol más activo que pudiera "poner en riesgo" el distinguido y privilegiado estatus epistemológico de la ciencia y, por ende, aspirar a su desacralización: "La legitimidad del 
conocimiento depende del reconocimiento que éste logre no solamente entre pares expertos sino por parte del público en general. La ciencia, al igual que el lenguaje, sólo son posibles como procesos colectivos. El conocimiento es un bien público" (Ibid, p. 81). La ciencia y la tecnología deben incluirse en espacios que cubren temas de mayor interés público: la economía, la política, la salud, la ecología, las comunicaciones, la educación, etc.: "Los medios de comunicación deben facilitar el acceso público a los contextos, procesos y métodos de producción científica y tecnológica no solamente a sus productos finales y así fomentar en el público el espíritu crítico y reflexivo sobre el papel de la ciencia y la tecnología en la sociedad." (Ibid, p. 83).

Como sostiene López Cerezo (2005, p. 351), aun en los medios académicos la comprensión de fenómenos como la cultura científica y la participación ciudadana, es bastante deficiente y lastrada por el tradicional modelo de déficit cognitivo y por una concepción simplemente instrumental de la participación. No obstante, en muchos países occidentales el creciente reconocimiento público y político de la ciencia y la tecnología, han derivado en una preocupación institucional por la alfabetización tecnocientífica de la ciudadanía, tanto en la educación formal como en algunos medios de comunicación: "La idea básica que subyace en la mayoría de las propuestas de alfabetización científica es que puesto que numerosas decisiones políticas están relacionadas con la ciencia y la tecnología es necesario que los ciudadanos posean ciertos conocimientos mínimos sobre dichas actividades. El concepto de cultura científica presupuesto es el de una comprensión mínima de los principales resultados de la ciencia y la tecnología y también el llamado 'método científico'." (Ibid, p. 353). En estas visiones o modelos lineales de difusión y de gestión del conocimiento se busca trasladar contenidos cognitivos desde A (expertos) hasta B (ciudadanos), simplificándolos al máximo para facilitar la máxima transferencia y asimilación de elementos

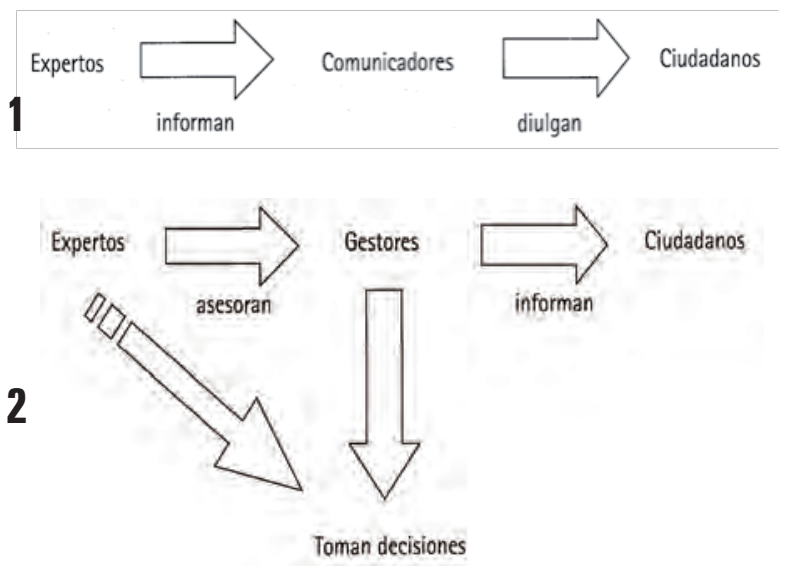

Figuras 1 y 2. Modelos de difusión y de gestión (López Cerezo, 2005, p. 354 y 355).

Para responder al desafío de superar esas visiones pasivas y lineales del proceso de enculturación así como para enriquecer una conceptualización de la cultura científica y tecnológica que contribuya al avance y consolidación de políticas públicas y de gestión más democráticas, López Cerezo propone un modelo interactivo de comunicación y gestión que no considera a los ciudadanos como receptores pasivos de elementos cognitivos forjados por expertos y mediatizados por comunicadores que se limitan a "traducir" la información técnica en un lenguaje accesible (ver figuras 3 y 4): "Se trata de diferentes culturas que deben ajustarse y acomodarse, la de legos y expertos, respondiendo a intereses, actitudes y valores propios; una empresa que requiere del buen hacer del facilitador profesional de la comunicación científica. El periodista científico debe aquí actuar como mediador activo entre legos y científicos, trasladando inquietudes, valores e información en un sentido, y conocimiento, incertidumbre y también valores en el otro" (Ibid, p. 356). Modelo interactivo de cultura científica y tecnológica en el que expertos, gestores y ciudadanos generan flujos de información donde los problemas e incertidumbres son puestos en común y son considerados desde diversas perspectivas. Así, un individuo científica y tecnológicamente culto no sólo alberga en su mente datos científico-tecnológicos e información especializada sino que está en capacidad de reflexionar y de enriquecer su propia experiencia usando esa información, de trascender 
la superstición y formarse juicios independientes sobre asuntos controvertidos acerca de la ciencia y la tecnología, en fin, de explicitar conscientemente interrogantes éticos y desafíos ambientales nacidos en las nuevas fronteras de la ciencia y la tecnología:

Una cultura científica de calidad es una cultura crítica y responsable, es conocimiento no sólo de las potencialidades de la ciencia sino también de sus incertidumbres, de sus riesgos, y de los interrogantes éticos que plantea. Es conciencia acerca del uso político de la ciencia en la arena pública, de su carácter de ciencia reguladora en la gestión, aunque también de la necesidad de la información científica para disponer de los mejores elementos de juicio. Es ser capaz de hacer uso de esa información al tomar decisiones de compra en el supermercado o en la exposición a una tecnología médica, como consumidor, como padre, como empresario o como trabajador. Estos rasgos cognitivos y comportamentales deberían ser considerados a la hora de conceptualizar y medir la cultura científica, atendiendo el valor personal y riqueza de ésta y no sólo a la cantidad de información asimilada (Ibid, p. 357).

La sociedad actual ha generado nuevas formas de participación y de experimentación personal que están estrechamente vinculadas con la promoción de la cultura tecnocientífica:

ciertas formas de protesta social individual y comunitaria, actitudes de consumo diferencial informado y reflexivo, interacción masiva de usuarios a través de Intenet en la generación de conocimientos, etc. En consecuencia, como muestra López Cerezo, ya no es posible concebir la cultura científica y tecnológica como "un prerequisito para la participación, como una tarea a desarrollar antes de dar el paso de la democratización”, por el contrario, la promoción de la cultura científica pasa por una alfabetización sustantiva a la vez que por "el desarrollo de una actitud de responsabilidad cívica que acompañe a esa alfabetización. Más aun, los diferentes modelos que puede asumir la particiapción pública pueden ser evaluados de acuerdo con su capacidad para que el proceso de participación genere aprendizaje social en relación con la ciencia y la tecnología, y por lo tanto cultura científica en la ciudadanía" (Ibid, p. 358).

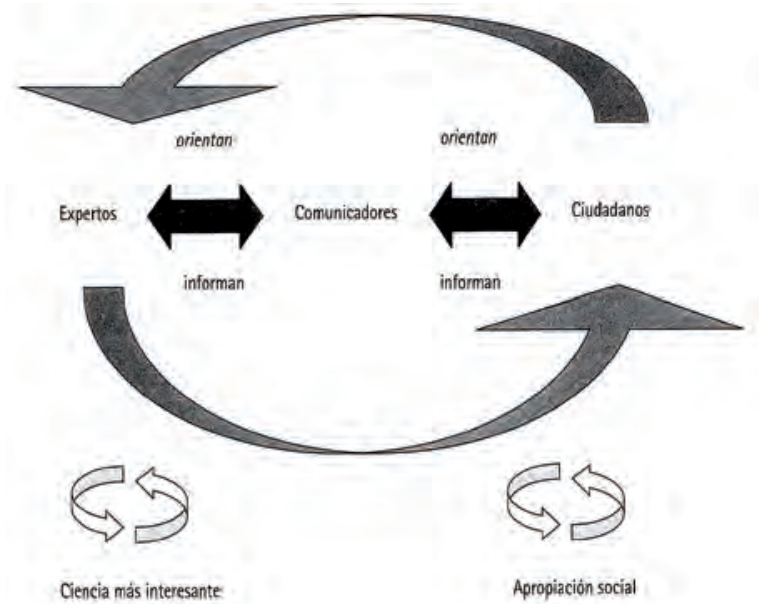

Figuras 3. Modelo interactivo de comunicación (López Cerezo, 2005, p. 355).

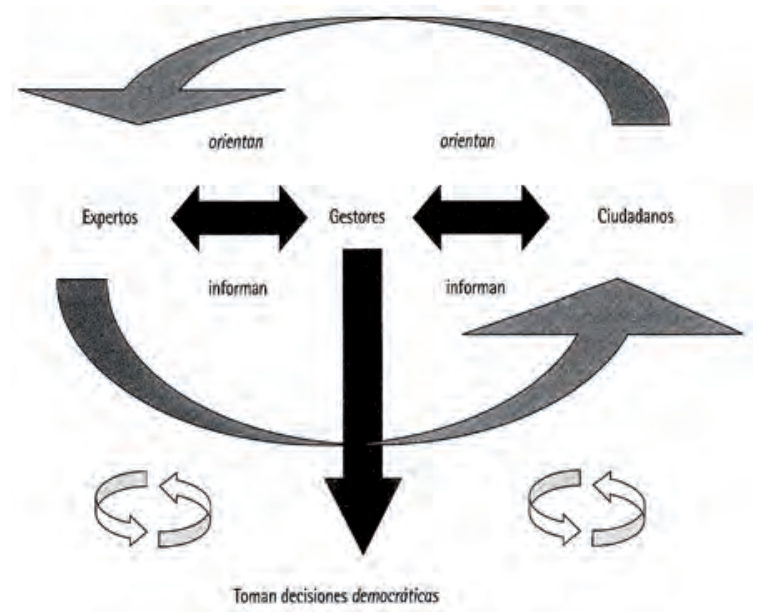

Figura 4. Modelo interactivo de gestión (López Cerezo, 2005, p. 356).

Condiciones comunicativas y publicitarias de una adecuada gobernanza de la ciencia y la tecnología 
La"gobernanza" esuntérminotomadodelinglésgovernance que, aunque ha sido traducido como "gobernabilidad" o "buen gobierno", no tiene una traducción literal en español. Es usado en el contexto de las ciencias sociales contemporáneas, especialmente las económicas y políticas, y se refiere al conjunto de instituciones, reglas, prácticas y acuerdos, formales 0 informales, de actores gubernamentales 0 no gubernamentales que diseñan políticas y toman decisiones sobre el devenir de la sociedad "posmoderna". El concepto se utiliza actualmente con por lo menos seis significados distintos: estado mínimo, gobierno corporativo, nueva gerencia pública, buen gobierno, sistemas social-cibernéticos y redes auto organizadas. Como establece el Libro Blanco de la Gobernanza Europea (White Paper on European Governance, 2001), son cinco los principios esenciales de la gobernanza: apertura, participación, responsabilidad, eficacia y coherencia. En síntesis, el objetivo de la gobernanza en el campo de la ciencia y la tecnología es mejorar el nivel de participación de los ciudadanos y de las organizaciones en el proceso de diseño de las políticas y orientaciones sobre el uso de conocimientos, aumentar el nivel de responsabilidad de los expertos y garantizar mecanismos de regulación frente a los riesgos y, finalmente, mantener la confianza de todos los que participan en unos procesos sociales complejos que no dejan de plantear incertidumbres y conflictos.

Como ya se ha mostrado, uno de los elementos fundamentales de una auténtica cultura científica y tecnológica tiene que ver con la apropiación social de la ciencia y la tecnología, en términos no meramente del consumo de sus productos acabados sino de la información requerida para la elaboración de juicios evaluativos de sus impactos y la toma crítica de decisiones respecto a su consumo. El otro factor clave para esa cultura es el de una participación ciudadana reflexiva y activa que haga viable la democratización de las políticas públicas respecto a la ciencia y la tecnología así como unas relaciones mucho más interactivas entre expertos y ciudadanos. Estas dos variables complementadas con una coherente responsabilidad social de los agentes (gobiernos y empresarios) que han llevado el liderazgo de los procesos de que venimos hablando y un sólido clima de confianza para afrontar todos los retos y riesgos que implica los procesos de renovación de valores, transformación de instituciones e innovación tecnocientífica, constituyen hoy las condiciones básicas de la gobernanza:

La gobernanza describe cómo la toma de decisiones en los procesos políticos está cambiando su naturaleza. En particular, la gobernanza de la ciencia y la tecnología nos conciencia sobre actualizadas propuestas que definen la política científica. [... ] Una de las propuestas es la gobernanza deliberativa, cuyo principal supuesto es que las políticas de ciencia y tecnología son producto de un intercambio abierto y recíproco entre comunidad científica y público. Bajo este supuesto, el público adquiere un papel diferente al tradicionalmente conocido como simple receptor de los resultados de tales políticas. Por lo que se presentan nuevos cambios: en la concepción del experto (condición ineludible para proponer proyectos de investigación), en las estrategias puestas en práctica para recoger demandas y, en definitiva, en la concepción de la política pública (Estévez, 2008, p. 1)

Ahora, en cuanto a la publicidad, aparte de su papel comercial, informativo o de entretenimiento, ella también cumple un papel clave como transmisor de valores de todo tipo e incluso como dispositivo ideológico. El entorno actual está saturado de una publicidad que trata de establecer un vínculo cada vez más emocional y sentimental con los consumidores, en su afán por incrementar y posicionar el valor de las marcas. Más que productos y servicios dicha publicidad ofrece modelos de vida, estereotipos de identidad y valores éticos que apuntan a una satisfacción de necesidades y aspiraciones de los ciudadanos de carácter fundamentalmente síquico y simbólico. Este poder de la publicidad que explota, muchas veces de manera fraudulenta y engañosa, la necesidad de distinción, 
reconocimiento y jerarquización de los consumidores, desemboca inevitablemente en problemáticas conductas de compra impulsiva, de adquisición descontrolada y adicción a productos y servicios tecnocientíficos "innecesarios" que llega a vulnerar la calidad de vida de muchos hogares.

\section{Normativas para el control y auto-regulación de la publicidad sobre novedades tecnocientíficas}

En vista de la vulnerabilidad de los ciudadanos frente a posibles manipulaciones que se cometen con algunos mensajes publicitarios, muchos gobiernos crearon regulaciones que buscan proteger a los consumidores, garantizar una competencia leal y defender derechos de autor. Y como parte de la formación ciudadana en una cultura tenocientífica es esencial la divulgación de esas normativas así como la identificación de casos de infracciones. Conforme con Wikipedia la publicidad engañosa es "aquella que, de cualquier forma -incluida su presentación-, induce o puede inducir a error a sus destinatarios, puede afectar su comportamiento económico o perjudicar 0 ser capaz de perjudicar a un competidor. La ley también entiende por engañosa la publicidad que silencia datos fundamentales de los bienes, actividades 0 servicios, siempre que dicha omisión induzca al error a los destinatarios"; en síntesis, es "aquella que oculta algún aspecto 0 información sobre lo que está anunciando así como aquella que induce a error al individuo dado que la información que transmite es dudosa 0 ambigua".

En lo que sigue presentaremos cronológicamente los aspectos centrales de algunas leyes y normas colombianas (decretos, códigos, resoluciones y reglamentos) que procuran establecer un control y regulación para evitar potenciales abusos cometidos desde prácticas de publicidad engañosa. Simultáneamente, abordaremos una serie de ejemplos de publicidad relativa a alimentos, artefactos, sustancias y servicios de todo tipo -todos los anuncios son tomados de la Revista Semana, entre los meses enerojunio de 2008- que, a partir de promesas de beneficios excepcionales y milagrosos obtenidos por el consumo de innovaciones atribuidas a la ciencia y la tecnología, violan muchos aspectos de dichas regulaciones. Esto se verá muy claramente, por ejemplo, en el caso productos que deberían evitar declaraciones ambiguas y falaces: "light", "bajo en grasas", "reduce el colesterol", "nutritivo", "sin azúcar", "alto contenido en fibra", "bajo en calorías", etc. La duda sobre estas denominaciones es iqué significan exactamente?, ¿qué cantidad hay que consumir?, ¿cuáles son las contraindicaciones y efectos secundarios? Como veremos, si antes de existir este tipo de normativas, las empresas podían afirmar lo que no estuviera explícitamente prohibido, ahora todas las aseveraciones que no se permitan expresamente en estos códigos (listados de declaraciones nutricionales y de salud) están completamente prohibidas.

La mayoría de países se han dotado de normativas que protegen a sus ciudadanos, productores y consumidores de prácticas desleales en la promoción comercial de productos que, eventualmente, puedan generar algún tipo de riesgos en el organismo humano y en el ambiente. En Estados Unidos, por ejemplo, La Comisión Federal de Comercio (Federal Trade Commission-FTC) es un organismo independiente establecido por el Congreso en 1914 para hacer cumplir la Ley de la Comisión Federal de Comercio. El artículo 5 de la Ley de la FTC prohíbe los métodos desleales de competencia y, modificado en 1938, además de prohibir los actos desleales y prácticas engañosas, también aplica una variedad de otras leyes antimonopolio y de protección de los consumidores.

No obstante, para despejar algunas dudas la FTC (1996) ha tomado la precaución de publicar estudios referentes a los mitos y verdades a medias que se han construido en torno a la publicidad engañosa.

En el Reino Unido, la mayoría de métodos y prácticas de la publicidad engañosa están prohibidas y estrictamente reguladas por la Agencia de Estándares de Publicidad (Advertising Standards Authority-ASA) y por la Oficina de 
Comercio Justo (Office of Fair Trading-OFT), mediante el Reglamento de control de la publicidad engañosa (The control of misleading advertisements regulations) de 1988 y enmendado en 2003. En Europa continental, se adoptó el Reglamento (CE) $\mathrm{N}^{\circ}$ 1924/2006 del Parlamento Europeo Relativo a las declaraciones nutricionales y de propiedades saludables en los alimentos, completo código con el que, más adelante, compararemos algunas normativas colombianas que de alguna manera lo tienen como referente.

Ya en Colombia, el Decreto presidencial 3466 de 1982, por el cual se reglamentaba la fabricación, comercialización, envase, rotulado o etiquetado, registro sanitario, control de calidad, vigilancia y control sanitario de los suplementos dietarios, ya se establecía que:

Toda información que se dé al consumidor acerca de los componentes y propiedades de los bienes y servicios que se ofrezcan al público deberá ser veraz y suficiente. Están prohibidas, por lo tanto, las marcas, las leyendas y la propaganda comercial que no corresponda a la realidad, así como las que induzcan o puedan inducir a error respecto de la naturaleza, el origen, el modo de fabricación, los componentes, los usos, el volumen, peso o medida, los precios, la forma de empleo, las características, las propiedades, la calidad, la idoneidad o la cantidad de los bienes o servicios ofrecidos. (Presidencia de la República de Colombia, 1982, artículo 14).

En 1998, la Comisión Nacional de Autorregulación Publicitaria (CONARP) adoptó el Código de Autorregulación como una "disposición de naturaleza ética, procedente de la voluntad privada del sector publicitario de establecer normas que rijan los contenidos del mensaje publicitario y establezcan responsabilidades y consecuencias para quienes deben someterse a sus lineamientos”. El alcance del Código abarca a los mensajes publicitarios emitidos a través de los medios de comunicación en el país así como a las distintas actividades publicitarias que buscan incentivar ventas directas pero, extrañamente, no se aplica a la publicidad política o electoral. Dispone que los anuncios publicitarios deben fundamentarse en los principios de la Decencia, Honestidad y Veracidad, que constituyen el marco filosófico de la Autorregulación (artículo 7). Y establece que "los anuncios deben respetar las normas y principios de la leal competencia. No podrán denigrar, confundir, ni realizar afirmaciones que no correspondan a la verdad en relación con productos, marcas o empresas de la competencia, ni atribuir a los productos anunciados características y calidades objetivas que no sean ciertas y comprobables" (artículo 9). En términos de la honestidad, los anuncios no podrán explotar la falta de conocimiento del consumidor ni abusar de su inexperiencia (artículo 13). La presentación debe ser verídica en cuanto a sus características, identificación, precio y forma de pago, condiciones de entrega, garantías, propiedad y reconocimientos o aprobaciones oficiales; además, el anuncio debe ser considerado como un todo ya que podría resultar falso aunque, literalmente, cada una de sus frases sea verdadera (artículo 15). Igualmente, respecto a las descripciones y argumentaciones del anuncio, el Código ordena que sean objetivas -"toda descripción, argumentación 0 afirmación que se haga, relacionada con hechos o datos objetivos, debe ser comprobable. Los responsables del anuncio deberán contar con las pruebas que sustenten sus afirmaciones objetivas con anterioridad a la difusión y deberán suministrarlas a las autoridades éticas competentes"- y no acepta las afirmaciones subjetivas pues buscan producir confusión y engaño (artículo 16). 


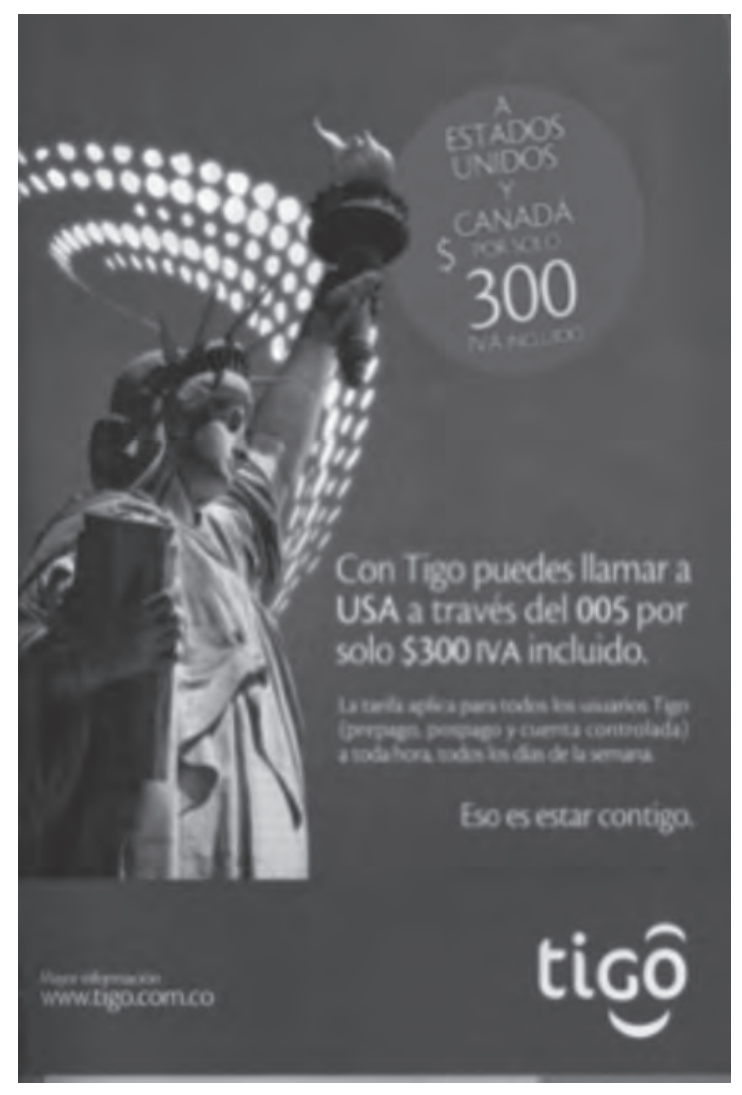

Figura 5

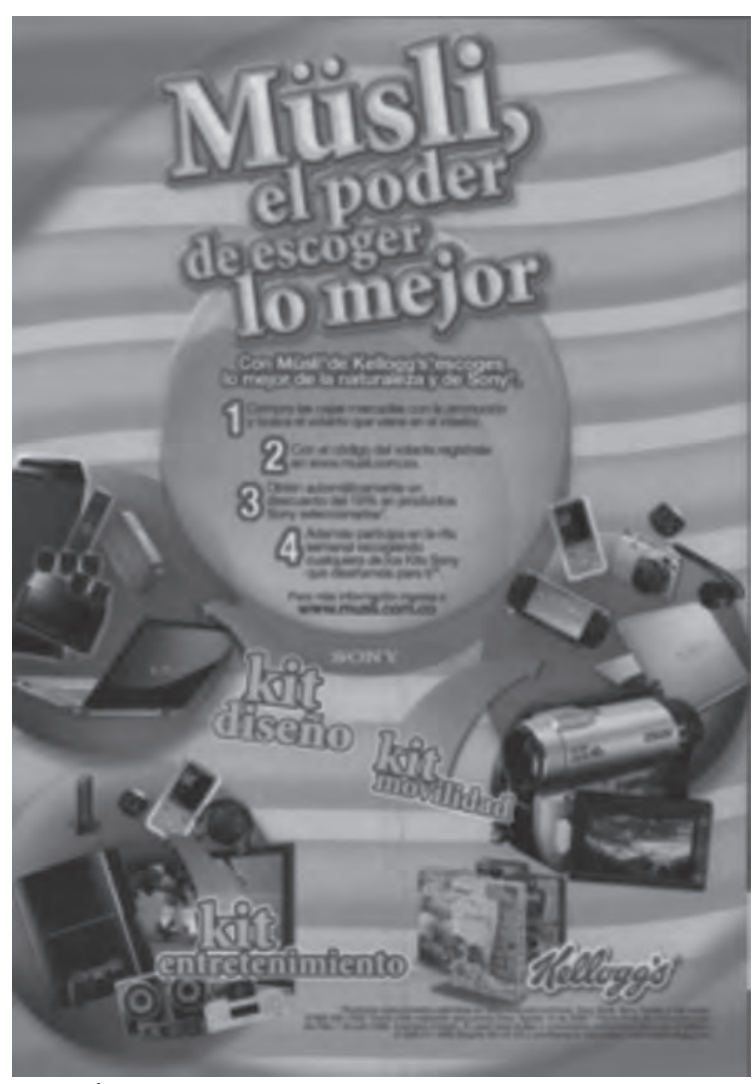

Figura 6

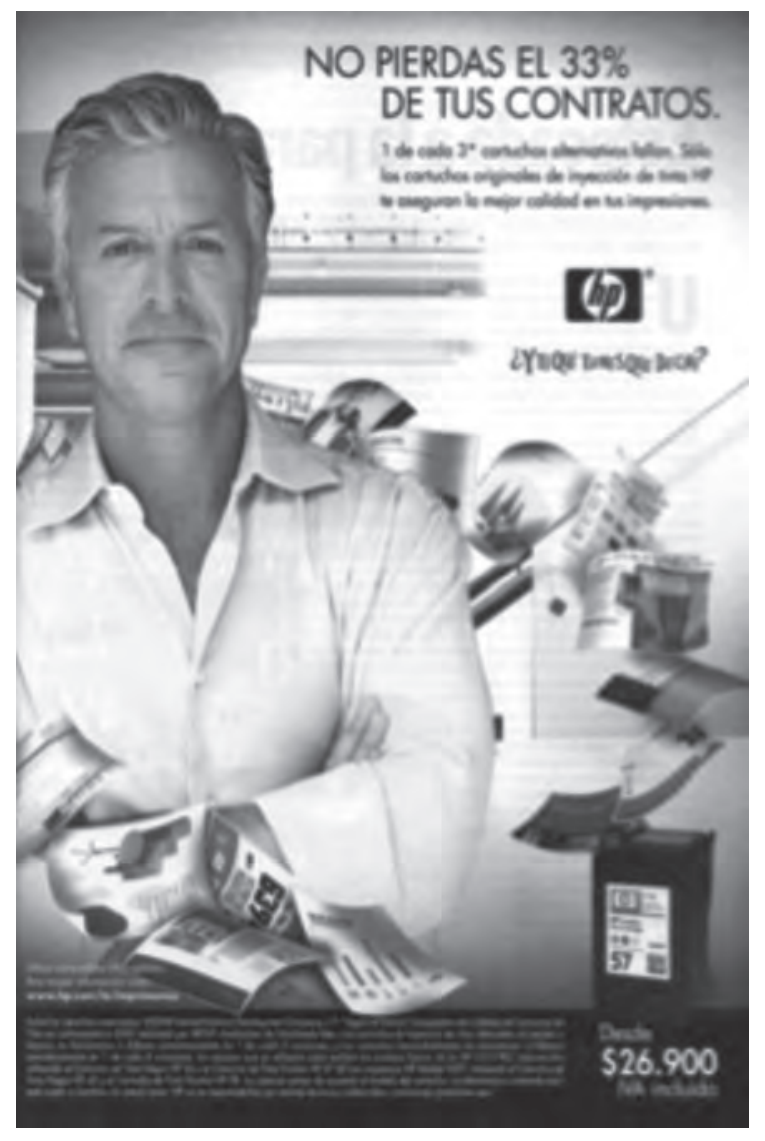

Figura7

Figuras 5-7. Ejemplos de anuncios donde hay confusión de datos.

Veamos, en el anuncio de Tigo (figura 5), la oferta dice que "Con Tigo puedes llamar a USA [Estados Unidos y Canadá] a través del 005 por sólo $\$ 300$ IVA incluido ... La tarifa aplica para todos los usuarios Tigo (prepago, pospago y cuenta controlada a toda hora, todos los días de la semana" (Semana $\mathrm{N}^{\circ} 1353$, p. 25). No obstante, luego de una revisión de las páginas web suministradas en el mismo anuncio, se encontró la siguiente tabla de tarifas que no coincide exactamente con la oferta: 


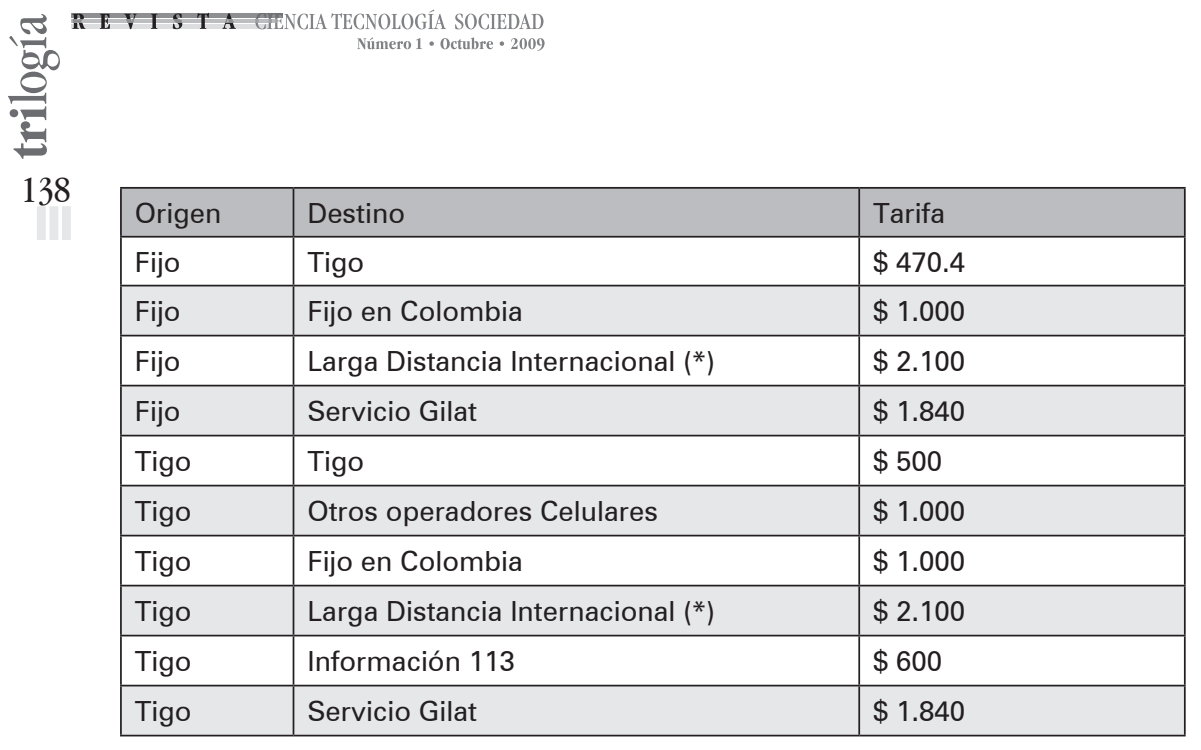

no contendrá, así sea en forma implícita, promesa científica ficticia 0 distorsionada" (artículo 18)

Tomado de: http://www.tigo.com.co/recargas.php (agosto 5 de 2008).

Sólo allí se aclara que son vigentes hasta el 31 de diciembre de 2008 y que pueden ser sujetas a modificaciones sin previo aviso (http://www.tigo.com.co/ larga_distancia.php, agosto 5 de 2008). La publicidad de Kellogg's (figura 6) dice "Müsli, el poder de escoger lo mejor. Con Müsli de Kellogg's escoges lo mejor de la naturaleza y de Sony" (Semana $\mathrm{N}^{\circ} 1360$, p. 69). Aunque se aclara que el inventario es limitado y se da un teléfono y una dirección para quién tenga dudas, la imagen es equívoca por cuanto tienen más peso los kit (diseño, movilidad y entretenimiento) de artefactos que el alimento mismo. En el aviso de HP (figura 7) sobresale la leyenda "No pierdas el $33 \%$ de tus contratos" y un subtítulo " 1 de cada $3 *$ cartuchos alternativos fallan. Sólo los cartuchos originales de inyección de tinta HP te aseguran la mejor calidad de tus impresiones" (Semana $\mathrm{N}^{\circ} 1361$, p. 45). Sin embargo, cuando se lee la letra menuda del asterisco (*) se cita el Estudio Comparativo de Calidad de Cartuchos de tinta en Latinoamérica 2007 realizado por BRTÜV Avaliacoes da Qualidade Ltda., donde se precisa que "los cartuchos remanufacturados no funcionaron o fallaron prematuramente en 1 de cada 4 ocasiones... La información contenida aquí está sujeta a cambios sin previo aviso. HP no se responsabiliza por errores técnicos o editoriales u omisiones contenidas aquí".

El Código de Autorregulación Publicitaria también estableció que "las referencias a investigaciones, encuestas o estadísticas deben contar con fuentes responsables, identificables y disponibles para su comprobabilidad. Los datos parciales de las investigaciones o estadísticas no pueden utilizarse para conducir a conclusiones distorsionadas" (artículo 17); igualmente, dictamina que "los anuncios sólo podrán utilizar información científica claramente identificada, comprobable y necesaria para la demostración de calidades objetivas del producto. El Anuncio

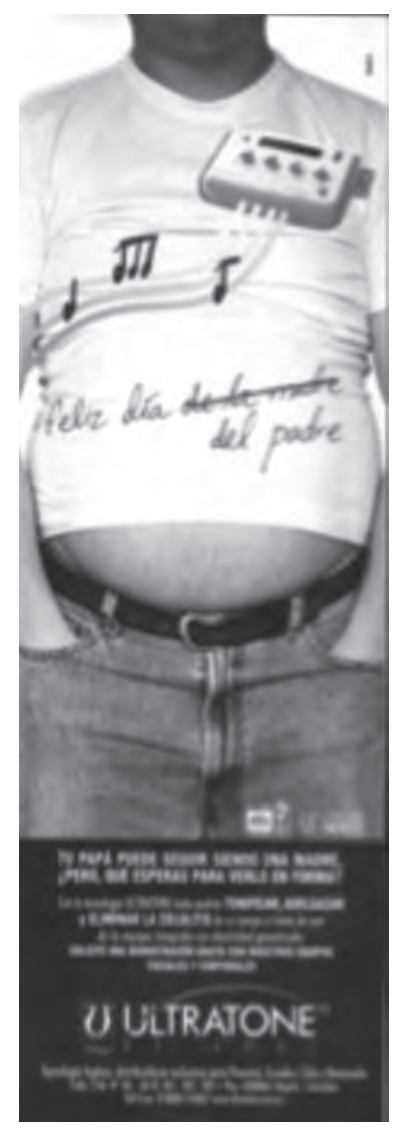

Figura 8

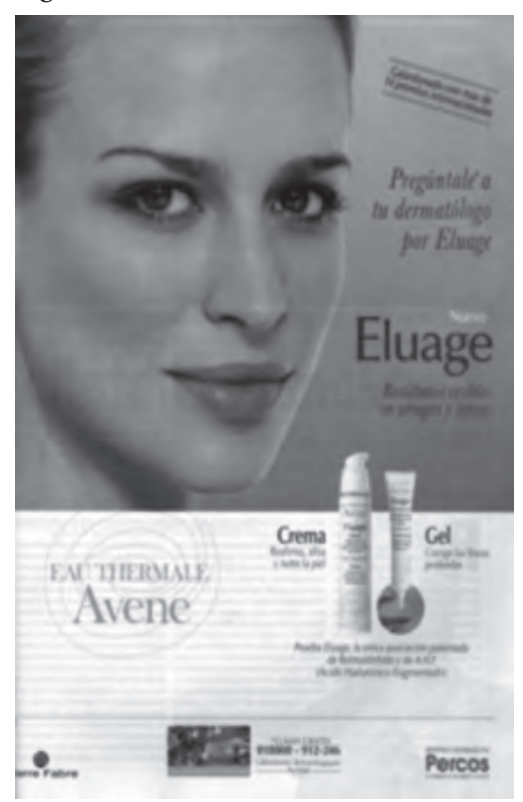




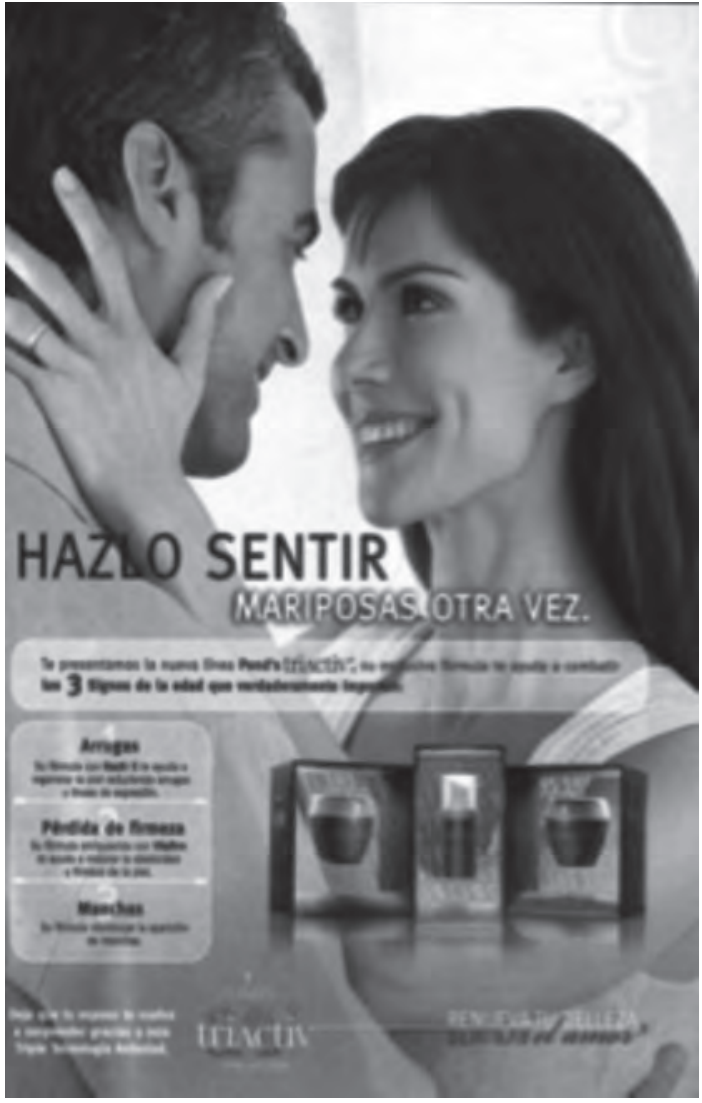

Figura10

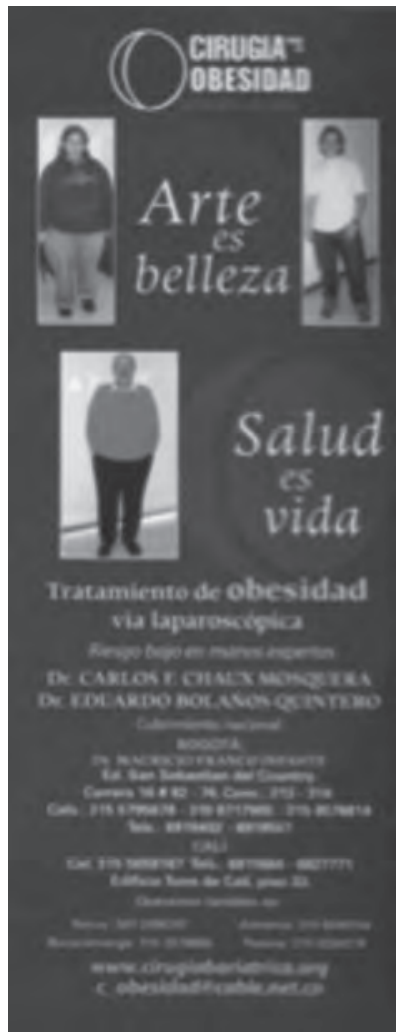

Figura 11

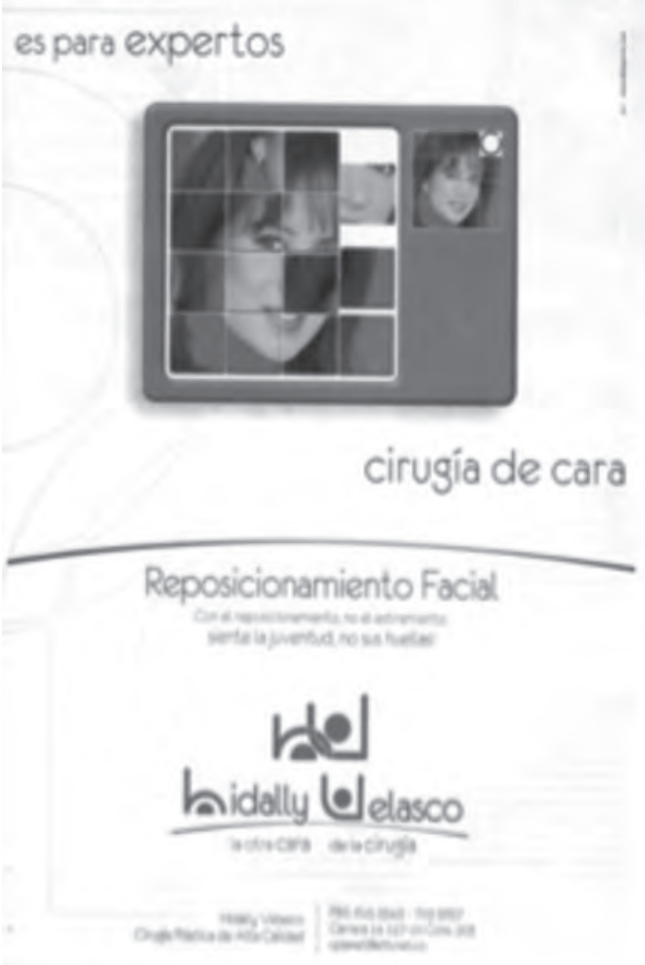

Figura 12

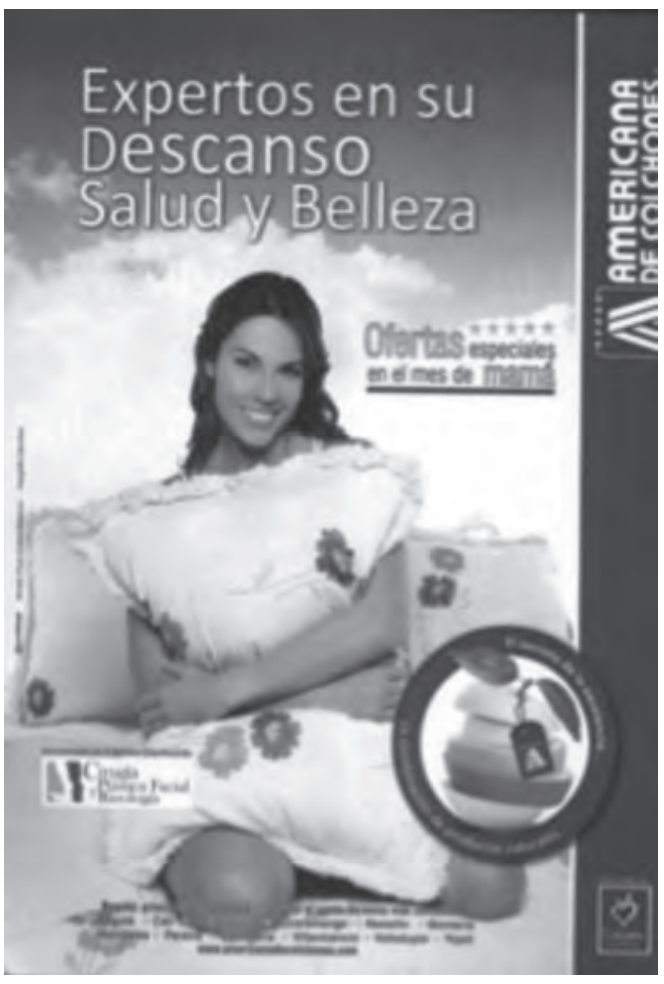

Figura 13 


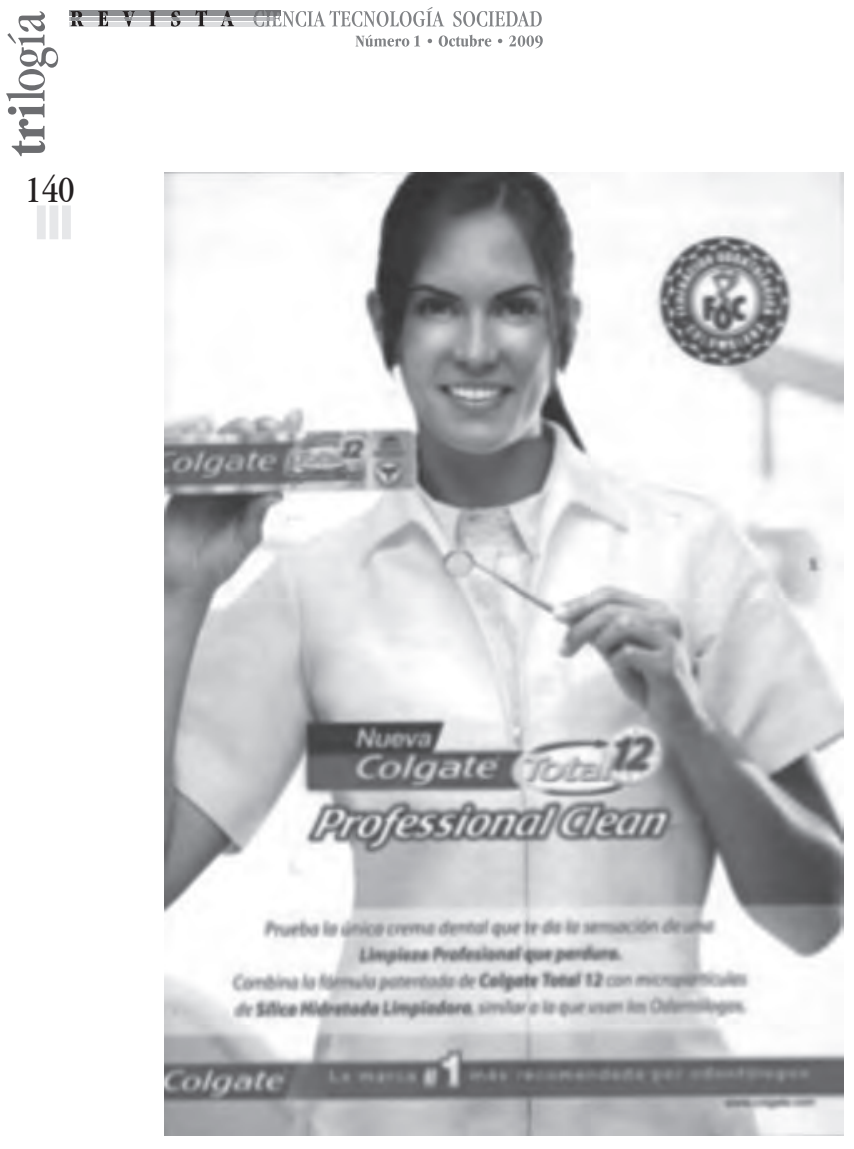

Figura 14

Figuras 8-14. Ejemplos de anuncios no soportados en investigaciones satisfactorias.

En los siguientes anuncios, veremos claros ejemplos de promesas "expertas" no soportadas en pruebas, estudios o investigaciones que satisfagan los criterios definidos por el Código de Autorregulación. Ultratone (figura 8) desea un feliz día del padre (tiene tachada las palabras "de la madre" en la leyenda escrita en una abultada barriga): "Tu papá puede seguir siendo una madre ¿Pero, qué esperas para verlo en forma? [...] Con la tecnología de Ultratone todos podrán tonificar, adelgazar y eliminar la celulitis de su cuerpo [...] con efectividad garantizada" (Semana ${ }^{\circ}$ 1362, p. 15). Eluage Nuevo, Eau Thermale Avene (figura 9) recomienda preguntar al dermatólogo por Eulage y promete "Resultados visibles en arrugas y surcos"; además, afirma que ha sido galardonado con más de 14 premios internacionales pero no dice cuáles. Su crema supuestamente reafirma, alisa y nutre la piel; su gel corrige las líneas profundas: "Prueba Eulage, la única asociación patentada de Retinaldehído y de A.H.F. (Acido Hialurónico
Fragmentado)" (Semana $\mathrm{N}^{\circ} 1356$, p. 68-69). Por su parte, Ponds triactiv Línea anti-edad (figura 10) sugiere a las mujeres "Hazlo sentir mariposas otra vez" en tanto su "exclusiva" fórmula ayuda a combatir los 3 signos de la edad que verdaderamente importan: arrugas, pérdida de firmeza y manchas: "Deja que tu esposo te vuelva a sorprender gracias a esta Triple Tecnología Antiedad" (Semana $\mathrm{N}^{\circ}$ 1349, p. 83). La publicidad de Cirugía para la obesidad (figura 11) postula que: "Arte es belleza - Salud es vida"; se trata de un tratamiento de obesidad vía laparoscópica donde el riesgo, sin más detalles, está en "manos expertas" (Semana $\mathrm{N}^{\circ} 1343$, p. 11). Hidally Velasco (figura 12), como si se tratara de un anuncio de maquillajes, dice ser "La otra cara de la cirugía. Es para expertos. Cirugía de cara. Reposicionamiento facial. Con el reposicionamiento, no el estiramiento; siente la juventud, no sus huellas" (Semana $\mathrm{N}^{\circ}$ 1362, p. 57). Americana de Colchones (figura 13) se promociona así: "Expertos en su Descanso, Salud y Belleza. Recomendados por la Sociedad Colombiana de Cirugía Plástica Facial y Rinología" (Semana $\mathrm{N}^{\circ} 1356$, p. 14). Pero ¿qué tienen que ver los colchones con una sociedad de cirujanos plásticos? Colgate Total 12 (figura 14) ofrece su producto Professional Clean: "Limpieza profesional que perdura. Combina la fórmula patentada por Colgate Total 12 con micropartículas de Sílica Hidrata Limpiadora, similar a la que usan los odontólogos. La marca \# 1 recomendada por odontólogos" (Semana $N^{\circ} 1350$, p. 49); o sea que con el sello de la Federación Odontológica Colombiana, pretende representar al conjunto de odontólogos en el decreto de esa primera posición.

Respecto a la protección del medio ambiente, el Código de Autorregulación prescribe que "no podrán, directa 0 indirectamente, contener mensajes que estimulen o sean tolerantes con acciones contrarias a la protección del medio ambiente urbano o rural, la explotación, uso inadecuado o desperdicio de los recursos naturales" (artículo 32). Y acerca de los menores de edad, claramente determina que los anuncios "no podrán, directa 0 indirectamente, estimular expectativas irreales respecto de las cualidades 
o desempeño del producto" (artículo 40); además, los de "productos no constitutivos de la alimentación básica tales como aperitivos, dulces, golosinas, goma de mascar y bebidas con componentes artificiales no deberán aludir a que suplen la alimentación básica" (artículo 46); finalmente, exige que la publicidad "no podrá insinuar o desarrollar sentimientos de inferioridad al menor que no consuma el producto" (artículo 48).

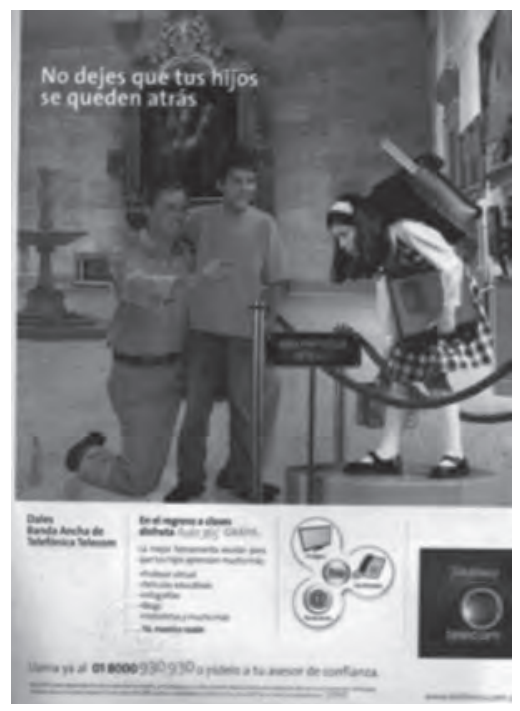

Figura 15

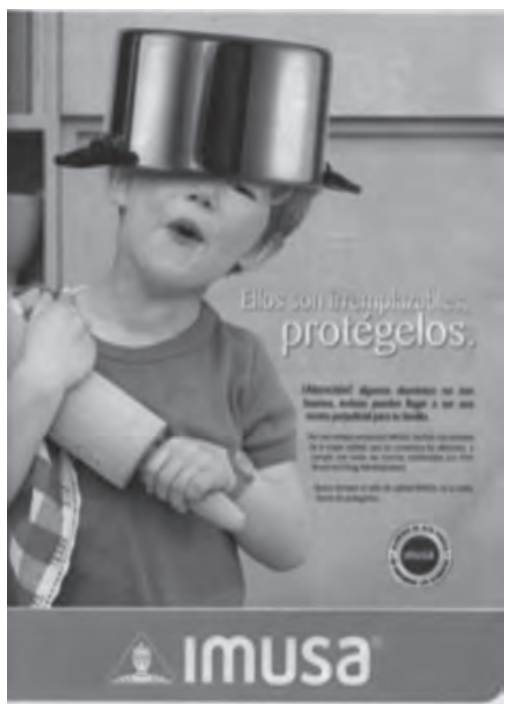

Figura 16

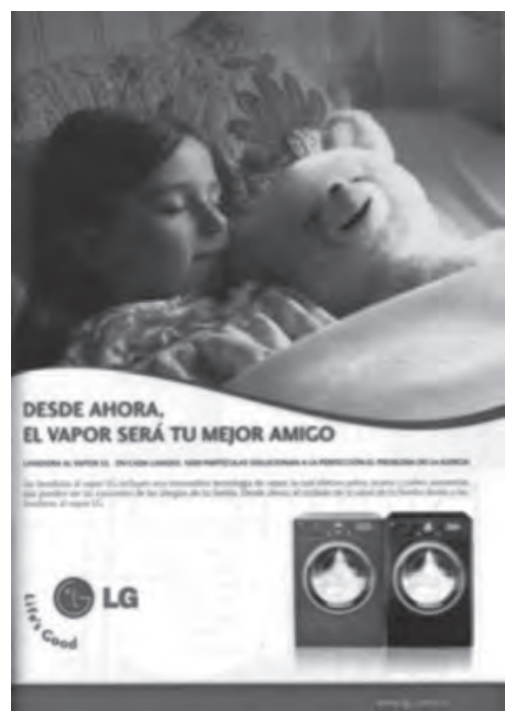

Figuras 15-17. Ejemplos de anuncios donde se explotan temores frente a los niños.

No obstante esto, exhibiendo una "Niña Phytecus" en un mueso, Telefónica Telecom (figura 15) intimida así: "No dejes que tus hijos se queden atrás [...] Dales Banda ancha de Telefónica telecom" (Semana $\mathrm{N}^{\circ}$ 1342, p. 12). Imusa (figura 16) recuerda que los niños "son irremplazables, protégelos”: "iAtención! Algunos aluminios no son buenos, incluso pueden llegar a ser una receta perjudicial para tu familia. Por eso compra productos Imusa, hechos con aluminio de la mejor calidad, que no contamina los alimentos y cumple con todas las normas establecidas por FDA (Food and Drug Administration)" (Semana N ${ }^{\circ} 1362$, p. 69). Y Lavadora al vapor LG (figura 17) promete incluso buena salud: "Desde ahora, el vapor será tu mejor amigo. En cada lavado, 1600 partículas solucionan a la perfección el problema de la alergia [...] incluyen una innovadora tecnología de vapor, la cual elimina polvo, ácaros y polen, sustancias que pueden ser las causantes de las alergias de tu familia. Desde ahora, el cuidado de la salud de tu familia dásela a las lavadoras al vapor $L G^{\prime \prime}\left(\right.$ Semana ${ }^{\circ} 1355$, p. 19).

Ahora, frente a los medicamentos, de acuerdo con el Código, la publicidad de éstos "no podrá hacer alusión a 
bondades, efectos, propiedades medicinales, preventivas o curativas, nutritivas o especiales que no se ajusten a la verdadera naturaleza de los productos anunciados, a su origen, composición o calidad, de acuerdo con las condiciones científicas y técnicas a las que se refiera el correspondiente registro sanitario" (artículo 49). En este importante campo de la salud, en la Resolución 24100 de 1996 del Instituto Nacional de Vigilancia de Medicamentos y Alimentos (INVIMA), por la cual se reglamentaba la publicidad de medicamentos, se creó el Comité de Publicidad de Medicamentos, compuesto por: el Jefe de División de Regulación y vigilancia de medicamentos o delegado, un delegado de la Dirección General, un profesional de planta de la subdirección de Licencias y Registros, un profesional de planta de la subdirección de Medicamentos y productos biológicos y un funcionario de la División de Regulación y vigilancia de medicamentos, quien coordinara permanentemente el Comité.

Como se aprecia, se trata de un comité completamente gubernamental y sin participación de ciudadanos, de empresarios, de gremios o de profesionales de la salud con quiénes concertar políticas públicas en este tema.

En la misma Resolución 24100 también se determinó que toda publicidad de medicamentos de venta libre dirigida al cuerpo médico, en medios masivos como radio, televisión, prensa, revista, afiches, folletos, plegables, y demás requiere del visto bueno previo otorgado por el INVIMA (artículo 7). Igualmente, que en la propaganda dirigida al cuerpo médico u odontológico, "deberán especificarse las indicaciones, usos terapéuticos, contraindicaciones, efectos colaterales, riesgos de administración o de farmacodependencia, precauciones y advertencias, sin omitir ninguna de las que figuren en la literatura científica o conozcan los fabricantes" (artículo 9). Allí mismo se precisaba que "la bibliografía sobre la cual se basa la información deberá citarse en forma clara y expresa; así mismo se debe identificar el principio activo con su nombre genérico, el cual irá en igualdad de caracteres a los del nombre o marca del medicamento". Finalmente, se establecía que la publicidad sobre medicamentos "deberá ceñirse a la verdad y no podrán exagerarse las bondades que puedan ofrecer" (artículo 10); también se prohibió la publicidad de medicamentos cuando expresara verdades parciales que induzcan a engaño o error (artículo 12).

Y en la Resolución 4536 del mismo año, el Ministerio de Salud prohibió la publicidad de medicamentos cuando:

a) Contraríe las normas generales aplicables en materia de educación sanitaria, nutrición o terapéutica; b) Exprese verdades parciales que induzcan a engaño 0 error; c) Impute, difame, cause perjuicios o comparación peyorativa para otras marcas, productos, servicios, empresas y organismos; d) Para medicamentos vendidos con fórmula médica, la promoción, bajo el sistema de premios en dinero o especie, por cuanto induce al uso irracional o sustitución de los mismos [...] y e) Los medicamentos con fórmula médica sólo podrán anunciarse 0 promocionarse en publicaciones de carácter científico o técnico dirigidas al cuerpo médico y odontológico; prohíbase su propaganda en prensa, radio, tv y cualquier otro medio de comunicación masiva (Ministerio de Salud, 1996, artículo 7).

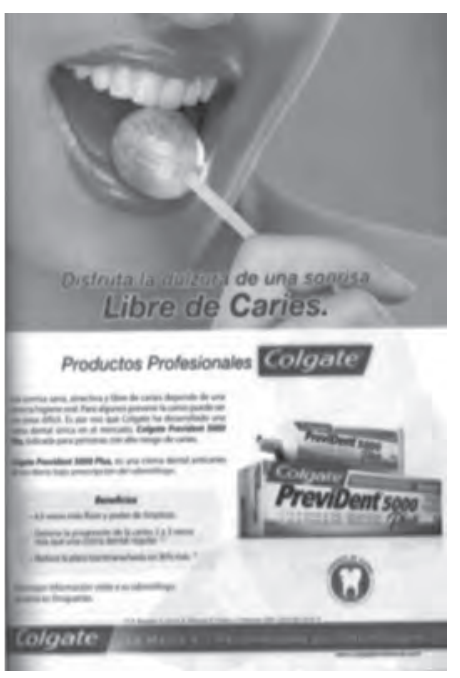

Figura 18 


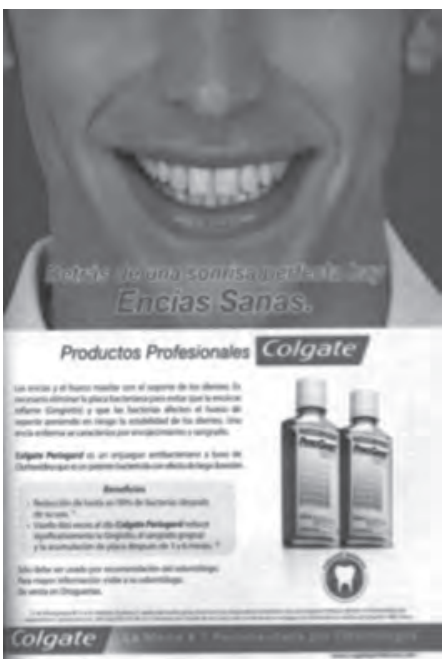

Figura 19

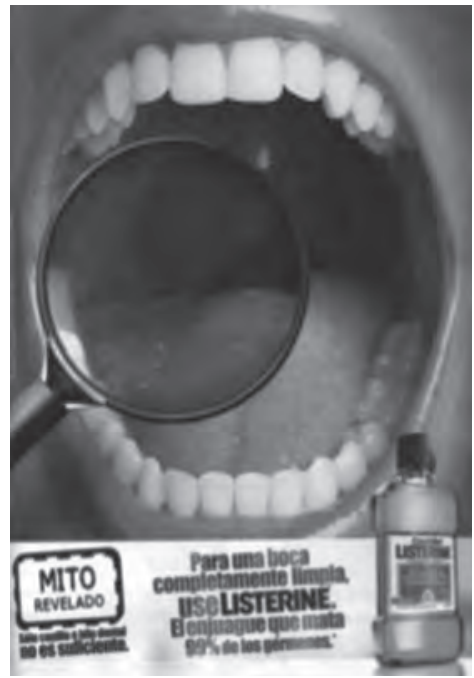

Figura 20

Figuras 18-20. Ejemplos de anuncios donde hay problemas con las fuentes de estudios citadas.

No obstante, Colgate Prevident 5000 Plus (figura 18) invita a disfrutar "de la dulzura de una sonrisa Libre de Caries. Una sonrisa sana, atractiva y libre de caries depende de una correcta higiene oral. [...] crema dental única en el mercado [...] indicada para personas con alto riesgo de caries" (Semana $\mathrm{N}^{\circ}$ 1352, p. 47). Entre sus supuestos beneficios: 4,5 más flúor y poder de limpieza, detiene la progresión de la caries 2 a 3 veces más que una crema regular, reduce la placa bacteriana hasta un 30\% más. Sin embargo, el estudio que se cita en letra menuda-A. Bayasan,
E. Lynch, R. Ellwood, R. Davies, L. Peterson 2001, Caries Res: 35: 41 4- no está disponible ni siquiera en internet. Colgate PerioGard (figura 19) sostiene que "Detrás de una sonrisa perfecta hay Encías Sanas. Colgate PerioGard es un enjuague antibacteriano a base de Clorhexidina que es un potente bactericida con efecto de larga duración" (Semana $\mathrm{N}^{\circ}$ 1352, p. 53). Entre sus beneficios: reducción de hasta un $99 \%$ de bacterias después de su uso, usado dos veces al día reduce significativamente la gingivitis, el sangrado gingival y la acumulación de placa después de 3 y 6 meses. Pero, igualmente, el primer estudio citado en la letra menuda -Alburquerque RF Jr et al, Reduction of salivary S. aureus and mutans group streptococci by preprocedural chlorhexidine rinse and maximal inhibitory dilutions of chlorhexidine and cetylpyridinium. Quintessence Int. 2004 Sep: 35(8) 635-40- sólo aparece disponible como abstract y el segundo -E. Grossman et al, Estudio de seis meses sobre los efectos de un enjuague con Chlorhexidina en adultos con gingivitis 1986 J. Perio- no está disponible ni en internet. Finalmente, Listerine Cool Mint (figura 20) se atreve a afirmar, sin demostrarlo e induciendo a error: "Mito Revelado. Sólo cepillo e hilo dental no es suficiente. Para una boca completamente limpia, use Listerine. El enjuague que mata 99\% de los gérmenes" que causan mal aliento, placa bacteriana y gingivitis (Semana $\left.\mathrm{N}^{\circ} 1361, \mathrm{p} .17\right)$.

Casi diez años más tarde, la Resolución 114 de 2004 del INVIMA, donde se intenta reglamentar la información promocional o publicitaria de los medicamentos de venta sin prescripción facultativa 0 venta libre, brinda ya una definición precisa de Medicamento:

Es aquel preparado farmacéutico obtenido a partir de principios activos, con o sin sustancias auxiliares, presentado bajo forma farmacéutica, que se utiliza para la prevención, alivio, diagnóstico, tratamiento, curación o rehabilitación de la enfermedad. Los envases, rótulos, etiquetas y empaques hacen parte integral del medicamento, por cuanto estos garantizan su calidad, estabilidad y uso adecuado. Medicamento de venta sin 
prescripción facultativa o venta libre: Medicamentos que el consumidor puede adquirir sin la mediación del prescriptor y que están destinados a la prevención, tratamiento 0 alivio de síntomas, signos o enfermedades leves que son reconocidas adecuadamente por los usuarios (Ministerio de la Protección Social, 2004, artículo 3).

En esta Resolución también se definen los requisitos para la publicidad de medicamentos de venta sin prescripción facultativa 0 venta libre:

1. Orientar la utilización correcta y racional del medicamento

2. Ser objetiva, veraz y sin exagerar sus propiedades.

3. Señalar las indicaciones o usos del medicamento, las cuales deben ser escritas en idioma español, utilizando un lenguaje claro que no genere confusión a los consumidores

4. Ser veraz, clara y precisa en lo referente a las indicaciones autorizadas del medicamento.

5. Respetar la libre competencia

6. Prescindir de términos técnicos que puedan generar confusión a los consumidores

7. Garantizar que la publicidad de las bondades del medicamento no se contraponga a la promoción de hábitos saludables

8. Garantizar que la información no induzca a error por afirmación o por omisión a prescriptores, dispensadores, ni a usuarios

9. Ajustarse al contenido de lo dispuesto en el registro sanitario del medicamento

10. Utilizar leyendas visibles, legibles en contraste y fijas cuando se trate de medios audiovisuales e impresos.

11. Difundir los mensajes en forma clara y pausada cuando se trate de medios radiales

12. No emplear mecanismos que atraigan la atención de los menores de edad induciéndolos al consumo (Ibid, artículo 5)
Finalmente, para la aprobación previa del INVIMA la solicitud de autorización de información publicitaria requiere anexar además del formato de solicitud firmado por el titular del registro sanitario o su apoderado debidamente acreditado, el proyecto de publicidad con las siguientes leyendas obligatorias: "Es un medicamento"; "No exceder su consumo"; "Número de registro sanitario"; "Leer indicaciones y contraindicaciones"; "Si los síntomas persisten, consultar al médico" (artículo 6).

Por lo que respecta a la fabricación, comercialización, envase, rotulado o etiquetado, registro sanitario, control de calidad, vigilancia y control sanitario de suplementos dietarios, el Decreto presidencial 3249 de 2006 brinda algunas definiciones más precisas que las existentes para tener en cuenta en las declaraciones publicitarias:

-Declaraciones de nutrientes: Es la relación 0 enumeración del contenido nutricional de un producto. -Declaraciones de propiedades en salud: Es toda información que afirme, sugiera 0 implique la existencia de una relación entre un componente contenido en los productos objeto del presente decreto y una condición de salud.

-Declaraciones de propiedades nutricionales: Se entiende por cualquier representación que afirme, sugiera 0 implique que un producto posee propiedades nutritivas particulares incluyendo pero no limitándose a su valor energético y contenido de vitaminas, minerales y oligoelementos.

-Suplemento dietario: Es aquel producto cuyo propósito es adicionar la dieta normal y que es fuente concentrada de nutrientes y otras sustancias con efecto fisiológico o nutricional que puede contener vitaminas, minerales, proteínas, aminoácidos, otros nutrientes y derivados de nutrientes, plantas, concentrados y extractos de plantas solas o en combinación (Presidencia de la República de Colombia, 2006, artículo 2). 
De acuerdo con este Decreto el Ministerio de la Protección Social, con el INVIMA, establecerán el listado inicial de declaraciones de propiedades aceptadas en Colombia para los suplementos dietarios, para lo cual tendrán en cuenta las aceptadas por la FDA (Food and Drugs Administration) o por la EFSA (European Food Safety Authority). El INVIMA actualizará el listado de acuerdo, entre otros, con estos lineamientos: debe efectuarse en forma tal que permita al público entender la información proporcionada y el significado de esa información; no se permite que aliente el consumo excesivo del producto; no deben generar dudas sobre alimentos y otros productos, ni suscitar temor en el consumidor acerca de los alimentos (artículo 6). En síntesis, esta publicidad se ajustará a los beneficios atribuidos a cada uno de los ingredientes característicos de la composición y deberá ser aprobada previamente por el INVIMA; además, "en el rótulo-etiqueta y en la publicidad no se deberá presentar información que confunda, exagere o engañe en cuanto a su composición, origen, efectos y otras propiedades del producto, ni ostentar indicaciones preventivas, de rehabilitación o terapéuticas" (artículo 24). De todas formas, la información del rotulado o etiquetado debe incluir esta leyenda preventiva: "ESTE PRODUCTO NO SIRVE PARA EL DIAGNÓSTICO, TRATAMIENTO, CURA O PREVENCIÓN DE ALGUNA ENFERMEDAD Y NO SUPLE UNA ALIMENTACIÓN EQUILIBRADA" (artículo 21, numeral 2, literal a). Y así como en el caso de los medicamentos, este Decreto también reglamenta los requisitos para la publicidad de suplementos dietarios:

1. Toda la información debe ser completa, veraz, que no induzca a confusión o engaño

2. Garantizar que la publicidad de las bondades de los suplementos dietarios no se contrapongan a la promoción de hábitos saludables y estilos de vida saludable en concordancia con las políticas de salud pública

3. No inducir o promover hábitos de alimentación nocivos para la salud

4. No afirmar que el producto llena por sí solo los requerimientos nutricionales del ser humano, o que puede sustituir alguna comida

5. No atribuir a los suplementos dietarios un valor nutritivo superior o distinto al que tenga

6. No realizar comparaciones en menoscabo de las propiedades de otros productos

7. No expresar o sugerir que la ingestión exclusiva de estos productos proporciona a las personas características 0 habilidades extraordinarias

8. No declarar propiedades que no puedan comprobarse, 0 que señalen que los productos son útiles para prevenir, aliviar, tratar o curar una enfermedad, trastorno 0 estado fisiológico

9. La leyenda de que trata el literal a), numeral 2 del artículo 21, deberá ser incluida en la publicidad de manera clara e inteligible

10. No incentivar el consumo en menores de edad.

11. Si la publicidad incluye promociones, no se permite que los incentivos estén en contacto con el contenido del producto (Ibid, artículo 25)

Si comparamos este Decreto 3249 con las reglamentaciones europeas a las declaraciones nutricionales y de propiedades saludables en los alimentos, se constata que la reglamentación colombiana coincide con muchas prescripciones del Reglamento (CE) $\mathrm{N}^{\circ}$ 1924/2006 del Parlamento Europeo y del Consejo de la Unión Europea. No obstante, la normativa europea es mucho más explícita y severa en ciertos criterios de seguridad respecto al etiquetado y la publicidad de los alimentos y de sus declaraciones nutricionales y propiedades saludables. Conforme al dictamen establecido por la Autoridad Europea de Seguridad Alimentaria, éstas deben ser veraces, claras, fiables y útiles para el consumidor a la hora de elegir una dieta saludable:

Deben establecerse los principios generales aplicables a todas las declaraciones relativas a un alimento con el fin de garantizar un elevado nivel de protección de los consumidores, dar a los consumidores la información necesaria para elegir con pleno conocimiento de causa, y crear condiciones iguales de competencia. [...] 
Actualmente se utiliza, en el etiquetado y publicidad de productos alimenticios en algunos estados miembros, una amplia variedad de declaraciones relativas a sustancias que no han demostrado ser beneficiosas 0 sobre las que no existe en la actualidad un consenso científico suficiente. Es necesario garantizar que las sustancias sobre las que se efectúa la declaración han demostrado poseer un efecto nutricional o fisiológico beneficioso. [...]

Es importante que las declaraciones de los alimentos puedan ser comprendidas por el consumidor y es conveniente que todos los consumidores estén protegidos de las declaraciones engañosas.

[...] Atendiendo al principio de proporcionalidad, el presente reglamento, con objeto de permitir la aplicación efectiva de las disposiciones de protección que contiene, toma como referencia al consumidor medio, que está normalmente informado y es razonablemente atento y perspicaz, teniendo en cuenta factores sociales, culturales y lingüísticos, según la interpretación que ha hecho de este concepto el Tribunal de Justicia, pero incluye además disposiciones encaminadas a impedir la explotación de consumidores cuyas características los hacen especialmente vulnerables a las declaraciones engañosas. [...] El fundamento científico debe ser el aspecto principal a tener en cuenta para el uso de declaraciones nutricionales y de propiedades saludables, y deben estar justificadas. Una declaración debe estar fundamentada científicamente mediante la toma en consideración de la totalidad de los datos científicos disponibles y la ponderación de las pruebas. [...] En aras de la transparencia y a fin de evitar una multiplicidad de solicitudes, la Comisión debe crear y actualizar un Registro público de las listas de esas declaraciones (Parlamento Europeo, 2006).

En el reglamento europeo se aplican definiciones como "etiquetado sobre propiedades nutritivas", "proteínas", "hidratos de carbono", "azúcares", "grasas", "saturados", "monoinsaturados", "poliinsaturados" y "fibra alimentaria"; además, se definen unos principios generales que debe cumplir cada declaración, la cual no deberá: a) ser falsa, ambigua o engañosa; b) dar lugar a dudas sobre la seguridad y/o la adecuación nutricional de otros alimentos; c) alentar o aprobar el consumo excesivo de un alimento; d) afirmar, sugerir o dar a entender que una dieta equilibrada y variada no puede proporcionar cantidades adecuadas de nutrientes en general; e) referirse a cambios en las funciones corporales que pudieran crear alarma en el consumidor o explotar su miedo, tanto textualmente como a través de representaciones pictóricas, gráficas 0 simbólicas (artículo 3). Este reglamento solamente autoriza el uso de declaraciones nutricionales y de propiedades saludables si se cumple la condición general de que "se ha demostrado que la presencia, ausencia o contenido reducido, en un alimento o una categoría de alimentos, de un nutriente $\mathrm{u}$ otra sustancia posee un efecto nutricional 0 fisiológico benéfico, establecido mediante pruebas científicas generalmente aceptadas" y "si cabe esperar que el consumidor medio comprenda los efectos benéficos tal como se expresan en la declaración" (artículo 5). En cuanto al fundamento científico de las declaraciones, éstas "deberán basarse y fundamentarse en pruebas científicas generalmente aceptadas" además de que el explotador de la empresa alimentaria "deberá justificar el uso de esa declaración" (artículo 6). De manera más específica, solamente se permiten las declaraciones de propiedades saludables que incluyan la siguiente información en el etiquetado o en la publicidad:

a) una declaración en la que se indique la importancia de una dieta variada y equilibrada y un estilo de vida saludable;

b) la cantidad de alimento y el patrón de consumo requeridos para obtener el efecto benéfico declarado;

c) en su caso, una declaración dirigida a las personas que deberían evitar el consumo del alimento; y

d) una advertencia adecuada en relación con los productos que pueden suponer un riesgo para la salud si se consumen en exceso (Ibid, artículo 10).

Asimismo, se estipulan algunas restricciones en el uso de propiedades saludables y no se autorizan las declaraciones que: a) sugieran que la salud podría verse afectada si no 
se consume el alimento de que se trate; b) las que hagan referencia al ritmo o magnitud de la pérdida de peso y c) las que hagan referencia a recomendaciones de médicos individuales $\mathrm{u}$ otros profesionales de la salud y otras asociaciones no mencionadas en el artículo 11 (artículo 12). Finalmente, en un anexo del reglamento se fijan límites cuantitativos para las declaraciones nutricionales: "bajo contenido de grasa" -sólo podrá declararse si el producto no contiene más de $3 \mathrm{~g}$ de grasa por $100 \mathrm{~g}$ en el caso de los sólidos o 1,5 g de grasa por $100 \mathrm{ml}$ en el caso de los líquidos-; "sin grasa" -sólo si el producto no contiene más de $0,5 \mathrm{~g}$ de grasa por $100 \mathrm{~g} 0100 \mathrm{ml}-\mathrm{y}$ se prohíben las declaraciones expresadas como " $\mathrm{X} \% \sin$ grasa"; "bajo contenido de azúcares" -sólo si el producto no contiene más de $5 \mathrm{~g}$ de azúcares por $100 \mathrm{~g}$ en el caso de los sólidos o 2,5 g de azúcares por $100 \mathrm{ml}$ en el caso de los líquidos-y "sin azúcares" -sólo si el producto no contiene más de $0,5 \mathrm{~g}$ de azúcares por $100 \mathrm{~g} 0100 \mathrm{ml}$. Respecto a esta información, en la figura 21 se pueden constatar los datos nutricionales que se contempla en las etiquetas, avaladas por la Food and Drug Administration de Estados Unidos (FDA), que permiten guiar a los consumidores de productos alimenticios:

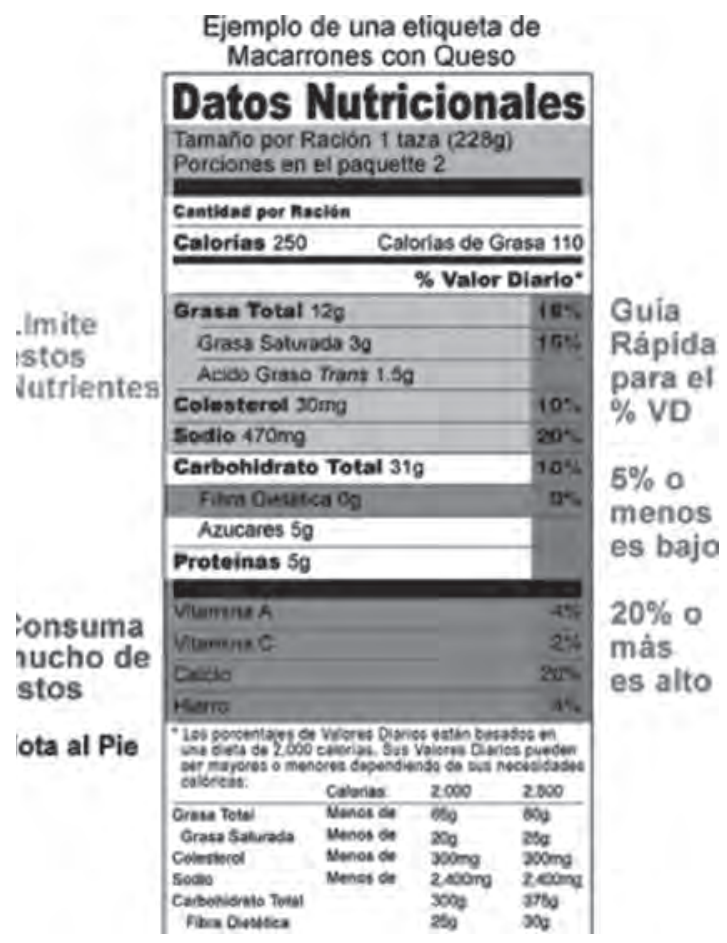

Figura 21. Etiqueta nutricional que guía el consumo de alimentos altos en colesterol o calorías (www.fda.gov/.../ ucm110019.htm).

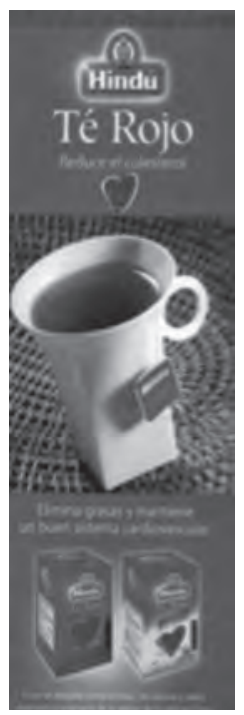

Figura 22

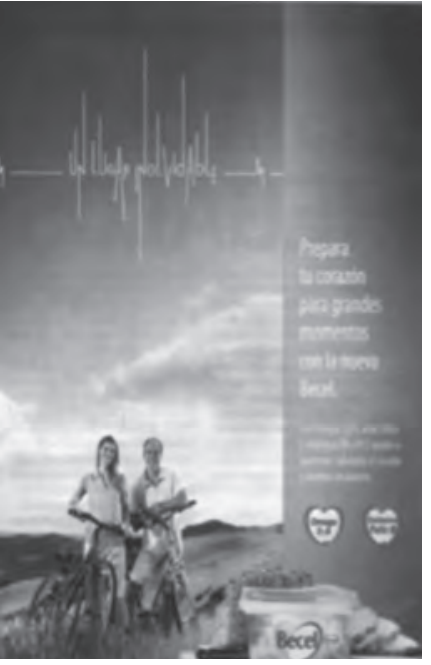

Figura 23

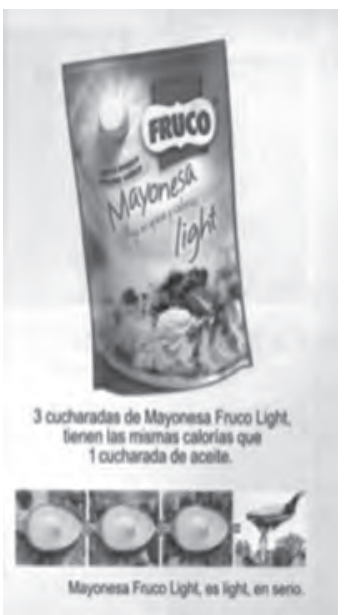

Figura 24 


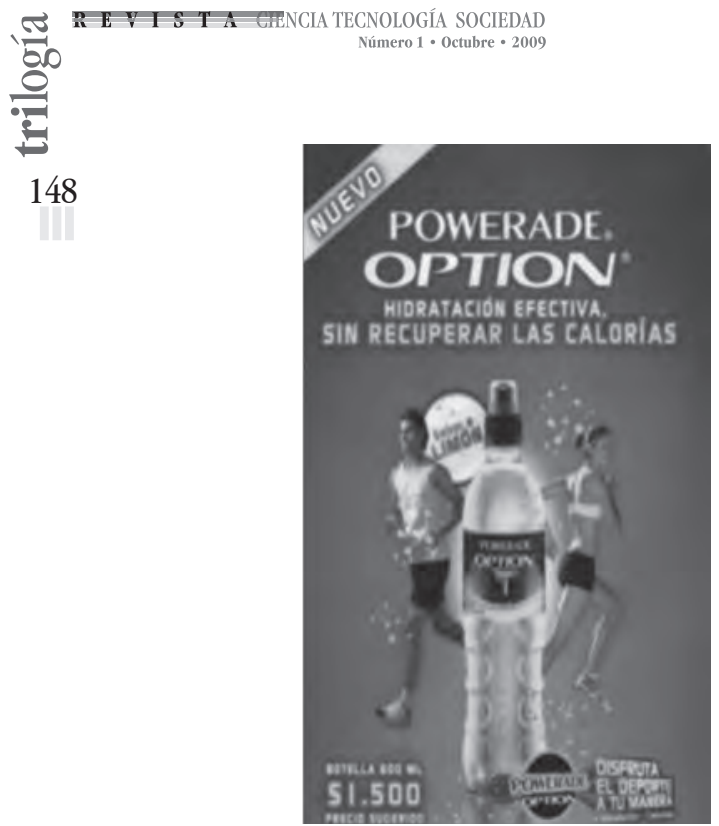

Figura 25

Figuras 22-25. Ejemplos de avisos de alimentos con propiedades nutricionales sin documentar.

Sin remitirnos a lo estipulado en el reglamento europeo sino al Decreto 3249, vemos como éste no se cumple en mucha publicidad colombiana de alimentos en tanto se exageran sus cualidades y no se suministra ninguna prueba de las propiedades milagrosas ofertadas. Por ejemplo, el Té Rojo Hindú (figura 22), originario de la región de Pu-erh en China, promete sin mostrar cómo que "Reduce el colesterol. Elimina grasas y mantiene un buen sistema cardiovascular" (Semana $\mathrm{N}^{\circ} 1349$, p. 107). La Mantequilla Becel (figura 23), representada en "un lugar inolvidable", asevera que "Prepara tu corazón para grandes momentos. Los Omegas 3 y 6 , ácido fólico y vitaminas B6 y B12 ayudan a mantener saludable el corazón y sistema circulatorio" (Semana $\mathrm{N}^{\circ}$ 1338-1339, p. 101). La Mayonesa Light de Fruco (figura 24) asegura, sin proporcionar más información, que es "Baja en grasas y calorías. 3 cucharadas de Mayonesa Fruco Light, tienen las mismas calorías que 1 cucharada de aceite [...] es light, en serio" (Semana $\mathrm{N}^{\circ} 1349$, p. 105). Y Powerade Option (figura 25) garantiza "Hidratación efectiva, sin recuperar las calorías" (Semana N ${ }^{\circ} 1346$, p. 95)

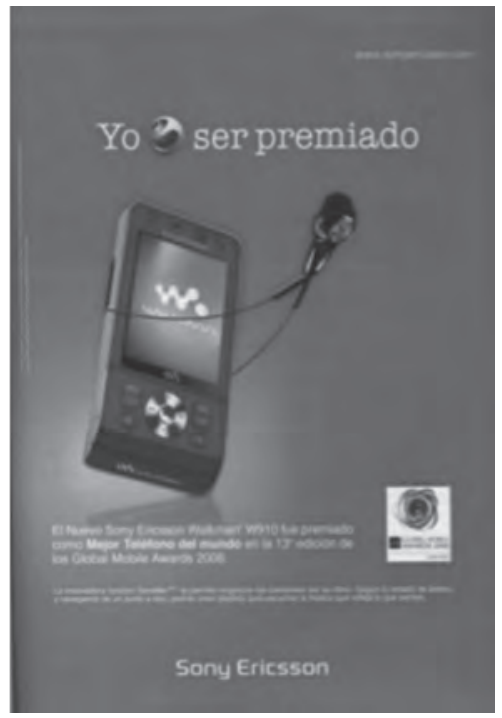

Figura 26

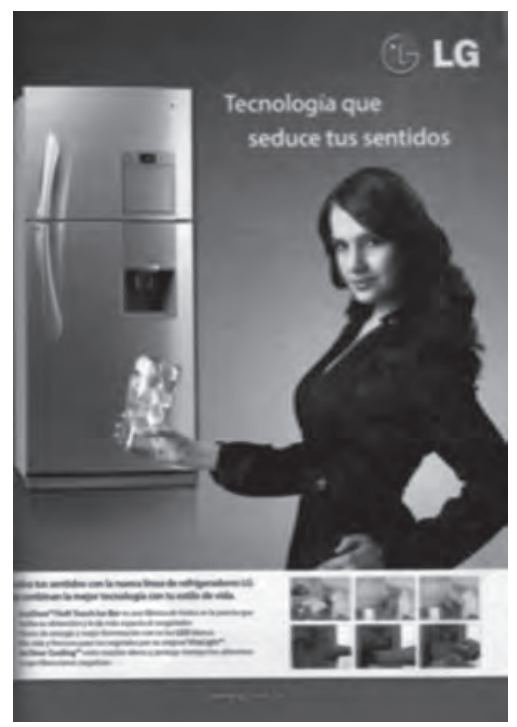

Figura 27

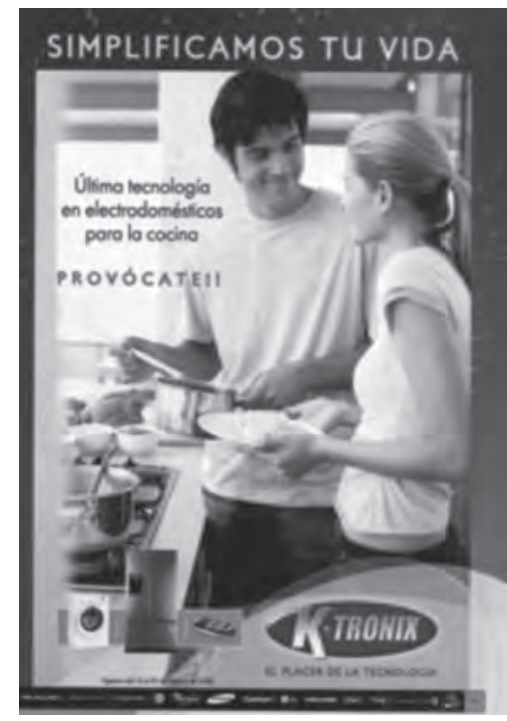

Figura 28 

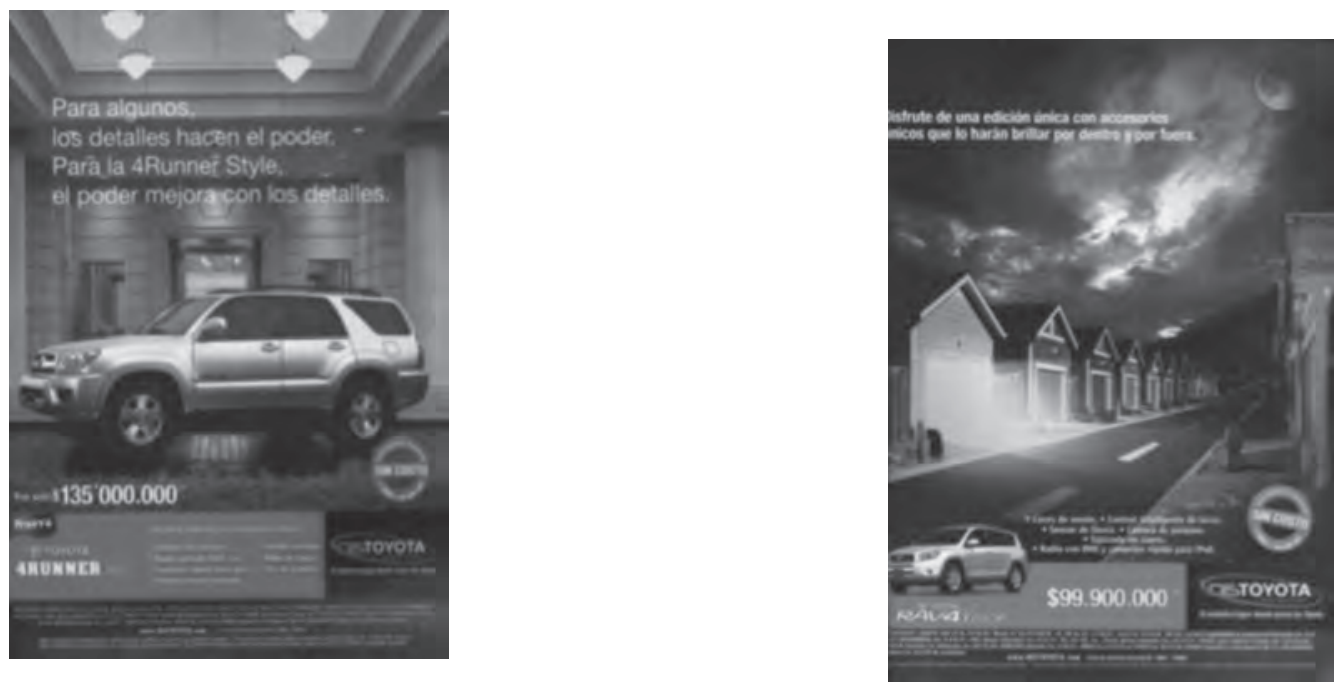

Figura 29

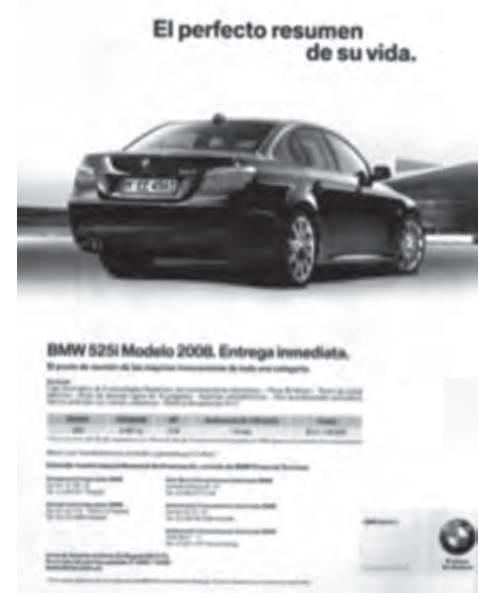

Figura 32

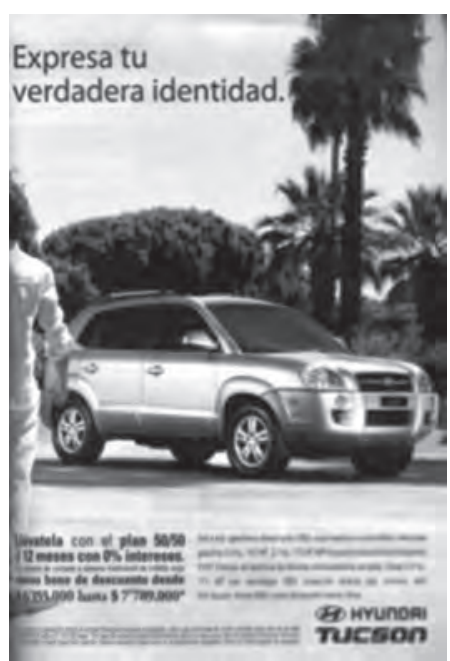

Figura 30

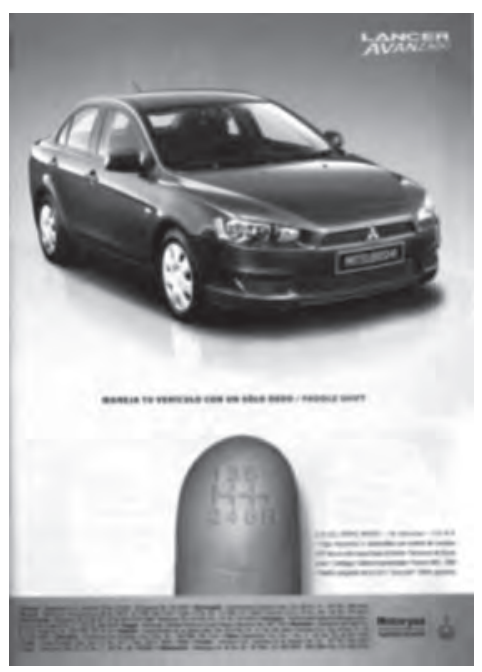

Figura 33

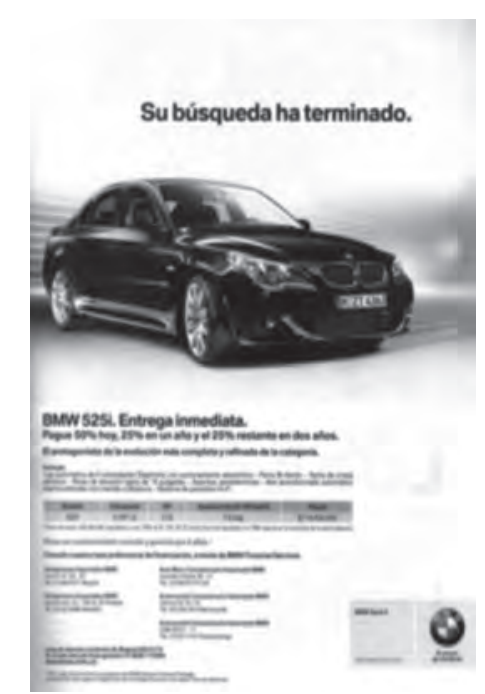

Figura 34

Figura 31

Figuras 26-34. Ejemplos de anuncios con promesas liberadoras y venturosas de la tecnología 
Para terminar este artículo, y en un ámbito menos explícito y más enfocado a aspectos sicológicos y simbólicos, presentamos algunos ejemplos de una publicidad que le otorga virtudes mesiánicas a la tecnología en tanto ofrece y explota supuestas opciones de seducción, confort, poder, identidad, liberación, felicidad, etc. Sony Ericsson (figura 26) hace gala de haber sido premiado: "El Nuevo Sony Ericsson Walkman W910 fue premiado como Mejor Teléfono del mundo en la $13^{\circ}$ edición de los Global Mobile Awards 2008" (Semana $\mathrm{N}^{\circ} 1353$, p. 36). No obstante, a la vez que lo ofrece "para escuchar la música que refleja lo que sientes" no aclara que ese premio de mejor microteléfono o dispositivo móvil lo comparte con el 3 Skypephone de 3UK. LG (figura 27) se promueve como "Tecnología que seduce tus sentidos": "Cautiva tus sentidos con la nueva línea de refrigeradores LG que combinan la mejor tecnología con tu estilo de vida"; tecnología Ion Door Coolling que "evita mezclar olores y protege siempre tus alimentos ya que libera iones negativos" (Semana $\mathrm{N}^{\circ}$ 1358, p. 49). K.Tronoix (figura 28) destaca "El placer de la tecnología. Simplificamos tu vida. Última tecnología en electrodomésticos para la cocina. Provócate" (Semana $\mathrm{N}^{\circ}$ 1346, p. 79). Capítulo aparte merece la publicidad de automóviles, artefacto sometido a la máxima mitificación y fetichización tecnológica: Toyota 4Runner Style (figura 29) se basa en el argumento de que "Para algunos, los detalles hacen el poder. Para la 4Runner Style, el poder mejora con los detalles"; detalles que se reducen a radio pantalla DVD con conexión rápida para iPod (Semana $\mathrm{N}^{\circ} 1360$, p. 89). BMW 525i Modelo 2008 (figura 30) se concibe como "El perfecto resumen de su vida. El placer de conducir. El punto de reunión de las mayores innovaciones de toda una categoría" (Semana $\mathrm{N}^{\circ} 1343$, p. 16). Mitsubishi Lancer Avanzado (figura 31) garantiza al usuario: "Maneja tu vehículo con un sólo dedo / Paddle Shift" (Semana $\mathrm{N}^{\circ}$ 1346, p. 21). Toyota Rav4 Visión (figura 32) basa su seducción en el eslogan "Disfrute de una edición única con accesorios únicos que lo harán brillar por dentro y por fuera"; accesorios "inútiles" como luces de xenón, control inteligente de luces, sensor de lluvia, cámara de parqueo, tapizado en cuero, radio con DVD y conexión rápida para
iPod (Semana $\mathrm{N}^{\circ} 1356$, p. 33). Hyundai Tucson (figura 33) le susurra al destinatario confundido con su personalidad "Expresa tu verdadera identidad" (Semana $\mathrm{N}^{\circ} 1352$, p. 33) y BMW 525i (figura 34), "el protagonista de la evolución más completa y refinada de la categoría", le asegura al individuo angustiado con el sentido de la vida que "Su búsqueda ha terminado" y que accederá al verdadero "placer de conducir" (Semana N ${ }^{\circ} 1359$, p. 23).

\section{Conclusión}

Un ciudadano apropiado de una cultura científica y tecnológica, desde la que conciba los productos del desarrollo y las innovaciones tecnocientíficas no como un logro acabado y milagroso sino como resultado de procesos económicos, sociales y políticos así como de interacciones entre saberes, agentes, artefactos y valores, estará mucho más capacitado para realizar evaluaciones y tomar decisiones de consumo más informadas, reflexivas y críticas respecto a la ingente cantidad de promesas que se le hacen desde la publicidad que circula por todo tipo de medios masivos e individualizados de comunicación. Y para la formación de esa cultura tecnocientífica que permita a los ciudadanos participar democráticamente en la discusión pública desde la que se toman decisiones sobre su porvenir, una tarea clave es la divulgación de las diferentes regulaciones que protegen al consumidor así como la identificación y evaluación crítica de casos donde posiblemente se vulneran esos códigos éticos.

\section{Bibliografía}

Blanco López, Ángel (2004). Relaciones entre la educación científica y la divulgación de la ciencia. Revista Eureka sobre Enseñanza y Divulgación de las Ciencias, 1(2), 70-86.

Castillo Bonilla, Andrés Jerónimo (1999). La publicidad y la publicidad engañosa. Tesis de Grado. Bogotá: Universidad Sergio Arboleda, Escuela de Derecho. Comisión de las Comunidades Europeas (2001). La 
Gobernanza Europea. Un Libro Blanco. Bruselas: Comisión Europea.

Comisión Nacional de Autorregulación Publicitaria (1998). Código de Autorregulación Publicitaria. Bogotá: CONARP.

Department of Trade and Industry of UK (1988) The Control of Misleading Advertisements Regulations. Disponible en:http://www.opsi.gov.uk/si/si1988/ Uksi_19880915_en_1.htm (mayo 22 de 2009). Domínguez, Raúl (1998). La publicidad como fuente de mal gusto. Revista de Extensión Cultural. Medellín: Universidad Nacional, $\mathrm{N}^{\circ}$ 40, diciembre de 1998, pág. 42-59.

Durandin, Guy (1982). La mentira en la propaganda política y en la publicidad. Barcelona: Paidós.

Eco, Umberto (2002). El mago y el científico. El País, diciembre 15 de 2002. Disponible en: http:// www.elpais.com/articulo/opinion/mago/cientifico/ elpepiopi/20021215elpepiopi_7/Tes (junio 16 de 2007).

Estévez Cedeño, Betty (2008). El papel del público en la gobernanza de la ciencia y la tecnología. Disponible en: http://www.oei.es/CongresoCiudadania/orales_ mesas/comunicacionoralBettyEstevezC.pdf (octubre 17 de 2008).

Federal Trade Commission de EEUU (1996). Myths and half-truths about deceptive advertising. Disponible en: http://www.ftc.gov/speeches/starek/nima96d4.shtm (marzo 4 de 2009).

Floch, Jean Marie (1993). Semiótica, marketing y comunicación. Barcelona: Paidós.

Guinsberg, Enrique (1987). Publicidad: manipulación para la reproducción. México: Plaza y Valdés.

Gutiérrez Julián, Marisa; Gómez Crespo, Miguel Ángel y Martín-Díaz, María Jesús (2002). ¿Es cultura la ciencia? En: Membiela, Pedro (ed.) Enseñanza de las ciencias desde la perspectiva ciencia-tecnologíasociedad. Formación científica para la ciudadanía. Madrid: Narcea.

Guzmán Hennessey, Manuel (2007). La ciencia sale del clóset. El Colombiano, noviembre 23 de 2007, p. 3.

Lévy-Leblond, Jean-Marc (2003). Una cultura sin cultura.

Reflexiones críticas sobre la "cultura científica".

Revista CTS, 1(1), 139-151.

López Cerezo, José Antonio (2005). Participación ciudadana y cultura científica. Arbor, CLXXXI(715), 351-362.

López Cerezo, José Antonio \& Luján, José Luis (2004) Cultura científica y participación formativa. En: Rubia, Francisco José; Fuentes, Isabel; Casado, Santos (eds.) Percepción social de la ciencia. Madrid: Academia Europea de Ciencias y Artes / UNED Ediciones, 29-45. Marcos, Alfredo y Calderón, Fernando (2002). Una teoría de la divulgación de la ciencia. Revista Colombiana de Filosofía de la Ciencia, 3(6-7), 7-40.

Marmori, Giancarlo (1977). Iconografía femenina y publicidad. Barcelona: Gustavo Gili.

Martínez Martínez, Inmaculada José (2003). La mujer y publicidad en España: contradicciones sociales y discursivas. Disponible en:http://www.razonypalabra. org.mx/libros/libros/mujerypublicidad.pdf (abril $17 \mathrm{de}$ 2009).

Ministerio de la Protección Social (2004). Resolución Número 004320 de 2004 Por la cual se reglamenta la publicidad de los medicamentos y productos fitoterapéuticos de venta sin prescripción facultativa o de venta libre. Bogotá: Ministerio de la Protección Social.

Ministerio de la Protección Social (2008). Resolución Número 0288 de 2008 Por la cual se establece el reglamento técnico sobre requisitos de rotulado o etiquetado nutricional que deben cumplir los alimentos envasados para consumo humano. Bogotá: Ministerio de la Protección Social.

Ministerio de la Protección Social/Instituto Nacional de Vigilancia de Medicamentos y Alimentos (1996) Resolución 24100 de 1996 Por la cual se reglamenta la publicidad de Medicamentos y se crea el Comité de Publicidad para su revisión y aprobación. Bogotá: Ministerio de la Protección Social/INVIMA. 
Ministerio de la Protección Social/Instituto Nacional de Vigilancia de Medicamentos y Alimentos (2004). Resolución Número 114 de 2004 Por la cual se reglamenta la información promocional o publicitaria de los medicamentos de venta sin prescripción facultativa o venta libre. Bogotá: Ministerio de la Protección Social/INVIMA.

Ministerio de Salud (1996). Resolución Número 4536 de 1996 Por la cual se reglamenta la publicidad de los medicamentos y se dictan otras disposiciones. Bogotá: Ministerio de Salud.

Nieto Olarte, Mauricio (2002). El público y las políticas de ciencia y tecnología. Interciencia, 27(2), 80-83.

Packard, V. (1957) Las formas ocultas de la propaganda. Buenos Aires: Editorial Sudamericana, 1972.

Packard, V. (1960) Los artífices del derroche. Buenos Aires: Editorial Sudamericana, 1983.

Parlamento Europeo (2006). Reglamento (CE) $\mathrm{N}^{\circ}$ 1924/2006 del Parlamento Europeo y del Consejo de 20 de diciembre de 2006 Relativo a las declaraciones nutricionales y de propiedades saludables en los alimentos. Diario Oficial de la Unión Europea, enero 18 de 2007. Bruselas: Parlamento Europeo.

Pérez Hernández, José María (1997). La mujer invisible, la mujer transparente. El discurso publicitario sobre los productos de higiene y belleza. Disponible en: http:// www.arrakis.es/jomperez/mujer1.html (enero 11 de 2009).

Perez Tornero, José Manuel et al (1992). La seducción opulenta: Publicidad, moda y consumo. Barcelona: Paidós.

Polino, Carmelo (2004). "Sabios" e "ignorantes", o una peligrosa distinción para América Latina. Journal of Science Communication, 3(3). Disponible en: http:// jcom.sissa.it/archive/03/03 (agosto 21 de 2007).

Presidencia de la República De Colombia (1982). Decreto 3466 de 1982 Por el cual se dictan normas relativas a la idoneidad, la calidad, las garantías, las marcas, las leyendas, las propagandas y la fijación pública de precios de bienes y servicios, la responsabilidad de sus productores, expendedores y proveedores, y se dictan otras disposiciones. Bogotá: Presidencia de la República de Colombia.

Presidencia de la República de Colombia (2006).

Decreto 3249 de 2006 Por el cual se reglamenta la fabricación, comercialización, envase, rotulado 0 etiquetado, régimen de registro sanitario, de control de calidad, de vigilancia sanitaria y control sanitario de los suplementos dietario. Bogotá: Presidencia de la República de Colombia.

Qualter, Terence (1994). Publicidad y democracia en la sociedad de masas. Barcelona: Paidós Ibérica.

Richards, Jef I. (1990). Deceptive Advertising: Behavioral Study of a Legal Concept. Florida: Florida State University.

Tapscott, Don y Williams, Anthony (2006). Wikinomics:

How mass collaboration changes everything. New York: Portfolio.

Victoroff, David (1980). La publicidad y la imagen.

Barcelona: Gustavo Gili. 
R E $\mathrm{Y}$ I $\mathrm{S}$ T A ERNCIA TECNOLOGÍA SOCIEDAD Número 1 - Octubre - 2009 '

을 


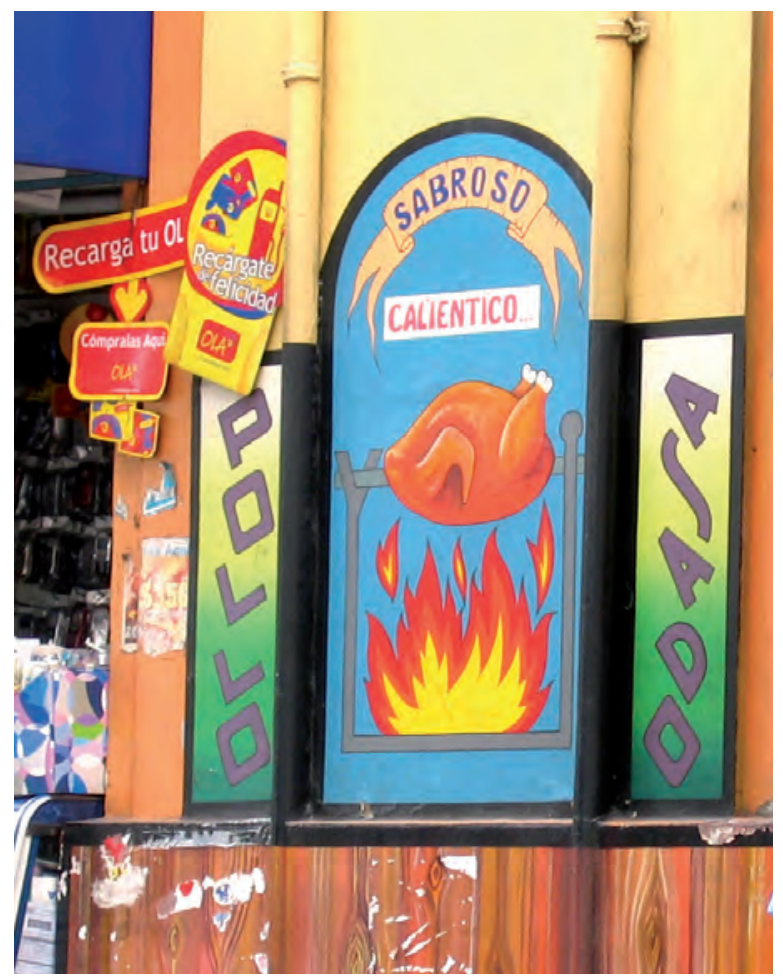

\section{Beta-6}

Un acelerador de partículas dispara.

Surgen, bombardeados, micro-objetos inestables: Poemas: Aparatos verbales. ¿Es la explosión total? ¿Es la gloria o es tan sólo un mesón lambda? ¡Oh secreta radiación!, noche plena que un día teclearon con palabras cuidadosas los líricos del alma, y ahora da miedo advertir que es real, real y nada. Lírica de Cámara, de la Cámara de Wilson, de la caja de sorpresas técnicamente explotada para bien de la verdad, para terror, para nada, para saber lo que son nuestras métricas palabras.

iOh poetas intimistas, líriqui-si-si, en ioh!, os adoro!

Por desgracia, deliciosos, sólo fuisteis un error de cálculo, un dolor, un jugar al yo-yo, iay!

Tanta música y estabais aún tocando el violón porque os creíais solos, y hasta le hablabais a Dios, y tan sólo existía a vuestro alrededor la estructura en que estabais como un bello detalle sin gran honor.

\section{Gabriel Celaya}

